\title{
Reductions of endogenous gibberellin content impact fruit development and modify tomato fruit metabolism during ripening
}

\author{
Auxiliadora 0. Martins
}

Universidade Federal de Vicosa

Welder A. Silva

Universidade Federal de Vicosa

Rebeca P. Omena-Garcia

Universidade Federal de Vicosa

Franciele S. Oliveira

Universidade Federal de Vicosa

José G. Vallarino

Universidad de Málaga: Universidad de Malaga

Sonia Osorio

Universidad de Málaga: Universidad de Malaga

Alisdair R. Fernie

Max-Planck-Gesellschaft

\section{Adriano Nunes-Nesi}

Universidade Federal de Vicosa

Dimas Mendes Ribeiro

Universidade Federal de Vicosa

Wagner Araujo ( $\nabla$ wlaraujo@ufv.br)

Universidade Federal de Vicosa https://orcid.org/0000-0002-4796-2616

\section{Research Article}

Keywords: flowering, fruit set, hormone, metabolism, Solanum lycopersicum

Posted Date: March 2nd, 2022

DOI: https://doi.org/10.21203/rs.3.rs-1363335/v1

License: (c) (1) This work is licensed under a Creative Commons Attribution 4.0 International License.

Read Full License 


\section{Abstract}

Gibberellins (GAs) play a crucial role in modulating developmental processes throughout the plant life cycle. Among the processes in which GAs are involved, they are of significance during the transition and maintenance of the reproductive meristem, as well as in allowing the floral organs development. GAs are also able to regulate, alongside with auxin and cytokinin, the initial processes of fruit development, most likely because they are responsible for both division and cell expansion. It is unknown whether fluctuations in the endogenous content of GAs impact fruit development and metabolism during ripening. To investigate these questions, tomato mutant plants deficient in GAs biosynthesis (gib3, moderately deficient; gib2, intermediate deficiency and gib1, extremely deficient in GA) were used. Notably, gib2 and gib1 mutants were characterized by a complete interruption of their reproductive development at the floral bud level. Although gib3 plants displayed a slightly delay in fruit development, at the end of fruit ripening both WT and gib3 fruits were highly similar. Little differences were found between WT and gib3 mutant plants during floral development and total fruit yield. We demonstrated that reduced GAs in gib3 mutant did not promote morphological modifications in fruits and relatively few metabolic changes were observed between genotypes during fruit ripening. Overall, typical metabolic changes, including increments in amino acids and soluble sugars coupled with reductions in starch, were observed during ripening. Collectively, we demonstrate that GAs plays a significant role on change vegetative to reproductive stage, as well as on the binging of set fruit.

\section{Key Message}

Tomato plants with reduced endogenous content of gibberellins show interruption or delay of the reproductive stage.

\section{Introduction}

The transition from vegetative to reproductive development is of great importance throughout the life cycle of plants (Galvão et al. 2015). In the case of angiosperm, reproductive success and the establishment of the germ line occurs only after this transition, i.e, the flowering process (Huang et al. 2017). A simplistic explanation of the flowering process is that a signal from the leaves moves to the shoot apex and induces flowering involving the integration of innumerable environmental signals (Bernier and Périlleux, 2005; Bouché et al. 2017). It has been also described that endogenous signals such as age and hormone levels are able to impact flowering time (Aya et al. 2009; Andrés et al. 2014; Zhang et al. 2016). Accordingly, the fruit set is characterized by the rapid development of the flower's ovary following the occurrence of pollination and consequent fertilization (Gillaspy et al. 1993; Serrani et al. 2007b; Shinozaki et al. 2016). This highly regulated sequence of events entails not only a strong imbalance of phytohormones but also a complex activation of programs for the ovule development (Obroucheva, 2014). 
The fruit, specific organ from angiosperm, can be classified in fresh and dry fruit and its development presents different phases (Knapp, 2002; Seymour and Granell, 2014). Recent studies have proposed four characteristic physiological stages occurring during fruit development process (McAtee et al. 2013; Obroucheva, 2014) rather than the three initially proposed (Gillaspy et al. 1993). Although both models are characterized by specific characteristics, a similar feature is the transition between vegetativereproductive processes that can occur gradually and with some overlap. The first stage is the fruit set that is mainly characterized by intense hormonal changes and the initial development of the embryo. During growth, which covers a long period, an intense division and cellular expansion occurs, thus determining the final fruit size. The maturation or breaker phase is a key point between final fruit growth and the ripening/senescence phase. In this stage, the fruit has reached the final size and all competence to ripen, although it has yet to start the ripening process (Ireland et al. 2013). The later stage is usually associated with significant metabolic and physiological changes (Klee and Giovannoni, 2011). Throughout fruit developmental process there is an exquisite crosstalk between different hormones. In addition to being stage-specific, the hormones involved with ripening/senescence in fruits may act both synergistically and antagonistically (Hanke et al. 2008; Huang et al. 2017; Batista-Silva et al. 2018). Gibberellins (GAs) are associated with the promotion of the vegetative to reproductive phase transition in plants (Pharis and King, 1985; Huang et al. 2017). Accordingly, GAs act in the establishment and maintenance of floral meristem (Olszewski et al. 2002; Gomez-Mena, 2005; Andrés et al. 2014) and at the development of floral organs such as petals (Hirano et al. 2008), anthers and pollen (Chhun et al. 2007; Zhang et al. 2010; Kwon et al. 2015) and carpet cells (Plackett et al. 2011). Together with auxin and cytokinin, GAs are required during early stages of fruit development (Gillaspy et al. 1993; Serrani et al. 2007a; McAtee et al. 2013). Thus, the content of GAs increase rapidly after fertilization of the ovary acting as a positive signal during the initial fruit development (Mapelli et al. 1978; Dorcey et al. 2009; Shinozaki et al. 2015). High concentrations of GAs are also found during the growth phase of the fruit. This is due to the fact that GAs play also a crucial role during the division process (Achard et al. 2009; Claeys et al. 2012; Sablowski and Carnier Dornelas, 2014) and cellular expansion (Bouquin, 2003; Locascio et al. 2013). In general, fruit set is result of successful ovule fertilization (Gillaspy et al. 1993; Olimpieri et al. 2007). However, ovary development can occur independently of this process, which leads to the formation of seedless, or parthenocarpic, fruit. Parthenocarpy may also occur in the nature for example with dead pollen or originating from incompatible species, as well as fertilization followed by embryo abortion. Accordingly, the parthenocarpy can also be artificially induced via increase in hormone content brought about genetic manipulation and/or exogenous application, more precisely involving auxin and GA. This process was further verified in plants with increased content and/or GAs signaling (Rieu et al. 2008; Livne et al. 2015) as well as in non-pollinated ovaries treated with exogenous Gas (Fos et al. 2001; Serrani et al. 2007a).

Regardless of the type of fruit development, the content of bioactive GAs decreases at the end of the growth phase being undetectable during the maturation and ripening phases (McAtee et al. 2013; BatistaSilva et al. 2018; Hu et al. 2019). During these last two stages fruits undergo highly regulated metabolic and physiological modification that affect the consistency, colour, flavour, and ultimately, taste of the fruit (Obroucheva, 2014; Zhang et al. 2015; Qin et al. 2016). In tomato fruits, this dramatic metabolic change is 
characterized by transition from the partially photosynthetic to the true heterotrophic metabolism, although the net photosynthesis seems not be important to fruits metabolism, but plays a significant role on seeds development (Lytovchenko et al. 2011). During this process, there is conversion from the chloroplast to the chromoplast with dominance of carotenoids and lycopenes in ripening (Carrari and Fernie, 2006). These authors also verified an extensive alteration in the contents of carbohydrates, organic acids and amino acids during fruit development reviewed in Batista-Silva et al. (2018). Wild type (WT) and gib3 mutant tomato plants showed a decoupling between the carbon and nitrogen metabolism in leaves, most likely due to the manipulation of the endogenous levels of Gas (Ribeiro et al. 2012b; Martins et al. 2019). Furthermore, immature tomato WT fruit are characterized by high levels of GA, whereas low GA levels were found in fruits of gib3 mutant plants with no significant GA levels in gib2 and gib1 fruits (Koornneef et al. 1990). Moreover, gib mutants are typical GA-responsive mutants, since reduced plant height, leaf size and flower morphology can be easily reversed to WT by GA application (Koornneef et al. 1990; Asahina et al. 2002). Here, we assess distinct aspects of the influence of GA levels on growth and primary metabolism of fruits through morphological, physiological and biochemical analysis of the GA tomato mutants during fruit development.

Our results demonstrate that impaired GA biosynthesis observed in gib1 and gib2 mutant plants (extremely and intermediate deficient in GA levels, respectively) strongly impacts juvenile-adult phase transition and the reproductive organs development. By contrast, the moderate deficiency in GAs observed in gib3 mutant plants culminated with morphological variations at the early stages of fruit development but was fully recovered following full fruit development. The effects of impaired GA biosynthesis appear to be fairly specific, particularly on floral establishment and metabolic reprogramming during fruit development.

\section{Material And Methods}

\section{Plant material and growth conditions}

The present work was conducted in Viçosa (20 45 'S, $42^{\circ} 15$ 'W, 650 m altitude), Minas Gerais, Brazil. Wild-type tomato plants (Solanum lycopersicum L. cv Moneymaker) (WT) and mutants deficient in biosynthesis of gibberellin ( $g i b 3$, moderately deficient in GAs; gib2, intermediate deficiency in GAs and gib1, extremely deficient in GAs) were kindly provided by Dr. M. Koornneef (Max Planck Institute for Plant Breeding Research, Cologne, Germany). Mutations in the initial enzymes of GA synthesis, namely entcopalyl diphosphate synthase and ent-caurene synthase, are found, respectively, in gib1 and gib3 mutants (Supplementary Fig. 1; Bensen and Zeevaart, (1990)). Both enzymes are located in plastids and only $6 \%$ and $7 \%$ of the total WT expression of ent-copalyl diphosphate synthase and ent-caurene synthase are observed in gib1 and gib3 mutant plants, respectively (Bensen and Zeevaart, 1990). In addition, a mutation in the gene encoding the ent-caurenic acid oxidase, an endoplasmic reticulum located enzyme, is found in gib2 mutant plants (Bensen and Zeevaart. 1990; Supplementary Fig. 1). It has been previous demonstrated that a very low GA like activity is observed in gib3 whereas it is negligible in gib2 and gib1 extracts (Koornneef et al. 1990). Taken together, these results provide 
compelling evidence that strongly reduced GAs levels are found in the mutant plants used here. The GA pathway highlighting the enzyme affected in each mutant and the vegetative phenotype of the mutants is additionally provide in Supplementary Fig. 1.

Germination was carried out in a growing chamber (Forma Scientific, Inc, Ohio, USA) under a photoperiod of $12 / 12 \mathrm{~h}$ (day/night), temperature $25 / 16^{\circ} \mathrm{C}$ (day/night), relative humidity $65 \pm 5 \%$ and light intensity of $150 \mu \mathrm{mol}$ photons $\mathrm{m}^{-2} \mathrm{~s}^{-1}$. After seven days, seedlings were transferred to plastic containers $(10 \mathrm{~L})$ containing commercial substrate and soil (50/50 v/v) supplemented, initially, with $14 \mathrm{~g}$ of NPK (4:14:8) per pot which means $0.56 \mathrm{~g}$ of $\mathrm{N}, 0.856 \mathrm{~g}$ of $\mathrm{P}\left(\mathrm{P}_{2} \mathrm{O}_{5}\right)$ and $0.93 \mathrm{~g}$ of $\mathrm{K}\left(\mathrm{K}_{2} \mathrm{O}\right)$ and fertilization throughout the experiment, as recommended for tomato cultivation (Nowaki et al. 2017). After transfer to pots, the plants were grown in a greenhouse under semi-controlled conditions (maximum photosynthetically active radiation (PAR) of c. $1500 \mu \mathrm{mol}$ photons $\mathrm{m}^{-2} \mathrm{~s}^{-1}$, with a mean temperature of $30 \pm 2{ }^{\circ} \mathrm{C}$ ). Plants were watered regularly and throughout the entire growth period the plants were maintained under naturally fluctuating conditions of light intensity, temperature and relative air humidity. The plants were irrigated daily as needed and no restriction of root development was observed at the end of the. The plants were maintained under these conditions for five months until the collection of vegetal material for the biochemical analyses, a posteriori. Two experiments were conducted in parallel, one for the evaluation of total fruits production and the second to analyse the reproductive process and fruit development.

\section{Evaluation of fruit development and total fruit production}

Wild type and mutants plants were grown side by side under greenhouse in the conditions described above and their development was closely observed until the production of fruits. Half part of plants was used to measure total fruit production and another half part was used to measure fruit development. Each single day, new flowers were tagged and the flowering and fruiting dates recorded on the tag. Index of floral fixation or percentage of flower abortion was determined by the difference between the number of flowers tagged and the total number of fully developed fruits. The fruits were harvested when they presented the reddish coloration characteristic of mature fruits. The fruit mean weight, total number and weight of the fruits per plant were measured as well as the fruit fresh and dry weights.

\section{Flowering evaluation}

The day when the plants start and end to flower was recorded for each plant. The following parameters were measured: the beginning of the flowering (emergence of the first inflorescence); inflorescence per plant; total number of flowers per inflorescence, as well as the average time of floral anthesis per inflorescence. Every single day, new flowers were tagged and the flowering and fruiting dates recorded on their respective tag, we also determined the percentage of floral abortion, calculated by the difference between the total number of flowers and the number of fruits produced per plant. The number of petals per flower and the viability of the pollen were also measured. Pollen grains were stained with acetocarmine and photographed using a digital camera (Axiocam MRc) coupled to stereo microscope (Zeiss 
model AX10). Pollen grains that presented abnormal size and transparent colouring were considered unfeasible.

\section{Fruit morphology}

Fruits morphology was determined in tagged fruits at 20 days after anthesis (DAA; mature green), 40 DAA (breaker stage) and $60 \mathrm{DAA}$ (ripe, but non-overripen) by determining their fresh and dry weight, diameter, height, volume and number of seeds. The fruits were oven-dried to constant dry weight at $72{ }^{\circ} \mathrm{C}$ for $72 \mathrm{~h}$. All these morphological analyses were carried out in at least 10 fruits/plants on each evaluated age, and we used at least five plants/genotype. Additionally, diameter and height measurements were performed in at least three different positions in each fruit to obtain an average measurement.

\section{Determination of fruit metabolite profiling}

Fruit mesocarp samples were taken from fruits with 20, 40 and 60 DAA and immediately frozen and powdered in liquid nitrogen, and then stored at $-80{ }^{\circ} \mathrm{C}$ until further analysis. All analysis (graphics) are expressed in dry weight.

Chlorophyll content ( $a$ and $b$ ) and total carotenoids were determined from $25 \mathrm{mg}$ fresh matter in $85 \%$ acetone extract at $4^{\circ} \mathrm{C}$, as described previously (Wellburn, 1994). The total chlorophyll contents $(a+b)$ as well as the chlorophyll a/b ratio was calculated. Approximately $5 \mathrm{mg}$ of dry matter (roots and leaves) were subjected to hot ethanol extraction by incubation at $70^{\circ} \mathrm{C}$ for $30 \mathrm{~min}$. In the ethanol-soluble fraction, the concentration of glucose, fructose and sucrose were measured as described previously (Fernie et al. 2001); total amino acids (Cross et al. 2006); malate and fumarate (Nunes-Nesi et al. 2007). In the ethanol insoluble fraction, it was determined starch contents (Fernie et al. 2001) and total soluble proteins contents by the Bradford technique (Bradford et al. 1976).

$\operatorname{NAD}(H)$ s and NADP $(H)$ s were determined as described previously by Gibon and Larher, (1997). Briefly, approximately $30 \mathrm{mg}$ of fresh matter were used and thus pyridine nucleotides were assayed using the phenazine methosulfate-catalysed reduction of dichlorophenolindophenol in the presence of ethanol and alcohol dehydrogenase (for NAD+ and NADH) or glucose 6-phosphate (G6P) and G6P dehydrogenase (for $\mathrm{NADP}+$ and NADPH). The equation used to determine the concentration of nucleotides was obtained by linear regression from a standard curve and subsequent normalization for the dry mass.

\section{Metabolite profiling}

Fruit pericarp samples ( $\pm 50 \mathrm{mg}$, fresh matter) were used to quantify the relative metabolite levels following an established gas chromatography mass spectrometry (GC-MS) based metabolite profiling method. The extraction, derivatization, standard addition, and sample injection were performed exactly as previously described Lisec et al. (2006). The mass spectra were cross-referenced with those in the Golm Metabolome Database (Kopka et al. 2005). This analysis allowed the determination of approximately 50 different compounds, representing the main classes of compounds (amino acids, organic acids, sugars and others). 


\section{Gibberellin measurement}

Sample extraction and purification were carried out as described by Chiwocha et al. (2003) with minor modifications. In brief, approximately $600 \mu \mathrm{g}$ of leaf tissue were extracted by $24 \mathrm{~h}$ incubation in $30 \mathrm{ml}$ of 99:1 isopropanol:glacial acetic acid ( $\mathrm{v} / \mathrm{v}$ ) containing $15 \mathrm{ng}$ of each deuterium-labeled standards (d2-GA1, d2-GA3, and d2-GA4 whereas GA7 and 9 as external standards) at $4{ }^{\circ} \mathrm{C}$ in the dark (OlChemlm Ltd, Czech Republic). Then, supernatants were collected after centrifugation for $15 \mathrm{~min}$ at $300 \mathrm{~g}$. Extractions were repeated with $10 \mathrm{~mL}$ of 99:1 isopropanol:glacial acetic acid (v/v). Both supernatants were mixed and passed through $80 \%$ methanol pre-equilibrated SPE-C18 columns (Strata-X 33u Polymeric Reversed Phase, Phenomenex) and filtrates were collected on ice. Extracts were concentrated to complete dryness using Speed-Vac concentrator. The residues were dissolved in $300 \mu \mathrm{L}$ methanol, sonicated for $5 \mathrm{~min}$, centrifugated at $14000 \mathrm{~g}$ for $8 \mathrm{~min}$ and the supernatants were passed through $0.2 \mu \mathrm{m}$ syringe filters prior UHPLC-MS/MS analysis. GAs analyses were performed using UHPLC-MS/MS system (UHPLC; Vanquish; Thermo Fisher Scientific) system coupled to a Q-Exactive-Orbitrap mass spectrometer (Thermo-Fisher). In total, $10 \mu \mathrm{L}$ of each sample were injected onto a Hypersil Gold C18 column $(3 \mu \mathrm{m}, 100 \times 2.1 \mathrm{~mm}$, Thermo Fisher Scientific). Samples were separated by a gradient elution of mobile phase A (water/methanol/acetic acid; 89.5/10/0.5) against an increasing percentage of mobile phase $B$ (methanol/acetic acid; 99.5/0.5). Quality control samples, internal standard and solvent blanks were also prepared and analyzed along with each batch of tissue samples.

\section{Statistical analyses}

Unless otherwise stated, data were obtained from 10 individual plants per genotype. The experiment was designed in a completely randomized distribution. The effect of genotypes was determined by analysis of variance $(P<0.05)$. The means were submitted to the Scott-Knott test. All statistical analyses were carried out using Statistical Analysis System (SAS; North Carolina State University, EUA).

\section{Results}

\section{The flowering of tomato plants is strongly affected by reduction in the endogenous ga levels}

Through quantitative analysis, via UHPLC-MS/MS, no differences in the content of the bioactive gibberellins GA1 and GA3 in any of the mutant plants was observed (Supplementary Fig. 2A-B). However, gradual reductions were observed in the content of the bioactive gibberellin GA4 in gib2 and gib1 mutant plants (Supplementary Fig. 2C), as was verified for the content of GA7, which was also reduced for the mutant gib3 (Supplementary Fig. 2C). In good agreement with the phenotype observed previously (Martins et al. 2019), gib1 mutant plants also displayed reductions in the content of GA9 (Supplementary Fig. 2E), which is the precursor of the bioactive GA4. 
From the simple visual inspection of WT plants when compared to gib3, gib2 and gib1 mutants, we observed a clear developmental reproductive pattern that was clearly different and characteristic among the tested genotypes. Similar to what was observed during vegetative stage in these mutants (Martins et al. 2019), reductions in the endogenous content of bioactive GAs also impacted the reproductive stage of these plants (Supplementary Fig. 1). Through visual and photographic monitoring for ten weeks, it was observed that the endogenous reduction of GA content strongly affects the reproductive development of these plants (Fig. 1). Wild type plants exhibited the first inflorescence three weeks after the transplant (35 days after sowing) whereas the appearance of inflorescences in plants with lower GA content was delayed by one week in relation to WT plants. Although gib3 mutant plants showed a vegetative development highly similar to WT, a delay in the appearance of the first inflorescence as well as in fruit emergence as long as one week was observed in relation to WT plants. Notably, in both gib2 and gib1 plants the inflorescence development was limited to the appearance of buds, which did not develop further in flowers (Fig. 1). By further analysing the development of the inflorescences in a more detailed manner, it was verified that only gib1 mutant plants produced a small number of inflorescences per plant in comparison to WT plants (Fig. 2A). Furthermore, the total number of flowers per inflorescence was higher in gib3 plants whereas it was significantly reduced in gib2 and gib1 plants in comparison to WT (Fig. 2B).

The anthesis period, i.e. the total time required (in days) for all flowers present in an inflorescence to fully open, was greater in approximately three days in gib3 in relation to WT plants (Fig. 2C). As previously demonstrated (Fig. 1), gib2 and gib1 mutant plants have no anthesis period since the buds are not able to develop in flowers, most likely due to the drastic reduction in the content of GAs. In addition, we observed that the number of unfeasible pollen grains was similar between WT and gib3 plants (Fig. 2D). Notably, this analysis was carried out solely in WT and gib3 plants, since in gib2 and gib1 the floral development is stalled before this step and can only be concluded with the addition of exogenous GA (Nester and Zeevaart, 1988; Jacobsen and Olszewski, 1991).

\section{Depletion in the ga level promotes delayed development of morphological characters during early stages of fruit development}

Given that both gib2 and gib1 mutant plants had their reproductive development fully impaired by the reduction of the endogenous content of GAs, all following analyses were performed only on fruits of WT and gib3 plants (Supplementary Fig. 3). There were no significant differences in total number of fruits per plant (Supplementary Fig. 3A), percentage of floral abortion (Supplementary Fig. 3B), the fresh and dry weight per fruit (Supplementary Fig. 3C-D), fresh and dry weight fruit/plant (Supplementary Fig. 3E-F), the dry weight/fresh weight ratio (Supplementary Fig. 3G) and the number of seeds per fruit (Supplementary Fig. $3 \mathrm{H})$. The relatively small reduction of the GA content in gib3 plants seems to not impact the full development of tomato fruits, since these analyses were carried out when the fruits were at the ripening stage. Thus, although the reduction of GAs in gib3 plants promoted a delay in the appearance and development of the inflorescences, both the production and morphology of the fully developed fruits were not altered in these plants. 
To further investigate to which extend the responses are similar during fruit development, we next decided to analyse fruits at different ages (Fig. 3). By analysing fruits harvested with 20, 40 and 60 days after floral anthesis (DAA) and comparing the genotypes effect on the fruit development, it was observed that height (Fig. 3A) and diameter (Fig. 3B) of 20 DAA fruits from gib3 plants were reduced in relation to the WT fruits. Despite of that, the total fresh weight (Fig. 3C), total dry weight (Fig. 3D), dry weight to fresh weight ratio (Fig. 3E) and volume (Fig. 3F) were not affected by the reduction in GA levels. We further observed that 40 DAA fruits of gib3 mutant were characterized by a significant reduction in their development in all evaluated traits, except for the percentage of DW that did not differ. Surprisingly, at 60 DAA the fruits of gib3 mutant plants were similar to WT fruits for most of the characters, except for the reduced values of dry weight and consequently affecting percentage of DW. This somehow growth recovery at 60 DAA indicated that the reduction of GAs in gib3 plants promotes morphological changes only at the temporal level, simultaneously with a slight delay in fruit development. The differences in time

effect between genotypes were also evaluated and, as expected, there were significant differences among the three developmental stages with progressive increments in the traits evaluated here. The percentage of fruit DW values did not differ at 20 and 40 DAA, but was significantly reduced at 60 DAA (Fig. 3E).

\section{Metabolic changes in response to variation of endogenous ga levels in tomato fruits}

Given the above-mentioned results and the visual aspects presented by the fruits in the different stages of development (Supplementary Fig. 4), we next decided to further perform an extensive metabolic analysis during fruit development. Changes in nitrogen metabolism were observed by the higher levels of chlorophyll a (Fig. 4A) in gib3 fruits at 20 DAA; however, this increase was not maintained in fruits of 40 DAA. Despite of these changes in chlorophyll a, the levels of chlorophyll b (Fig. 4B) and chlorophyll a/b ratio (Fig. 4C) were invariant between genotypes at 20 and 40 DAA. Since the fruits were already ripening at $60 \mathrm{DAA}$, the reduction of pigments was substantial, and they were not even detected at 60 DAA. Consistent with the chlorophyll results, total carotenoid contents (Fig. 4D) were gradually and significantly higher in the gib3 mutant than in WT at 40 and 60 DAA, although when we analyse each genotype over time, at 60 DAA presented a significant effect within the genotypes. The values of total amino acid (Fig. 4E) and soluble protein (Fig. 4F) exhibited a similar behaviour during fruit development. Total amino acid content was similar between WT and gib3 fruits at the different time points evaluated and significantly increased at 60 DAA in both genotypes (Fig. 4E). As for amino acids, protein content did not present significant differences between the genotypes at 20 and 40 DAA (Fig. 4F). The fruits of 60 DAA from gib3 mutant exhibited a reduction of $25 \%$ in the protein content in comparison with WT fruits. Noteworthy, proteins levels were significant and progressively increased throughout fruit development, and as such WT fruits presented three times higher content at 60 DAA when compared with 20 DAA.

In terms of metabolites directly related with carbon metabolism, we evaluated the contents of soluble sugars (glucose, fructose and sucrose), starch and the organic acids (malate and fumarate) (Fig. 5). Briefly, the levels of glucose (Fig. 5A), fructose (Fig. 5B) and sucrose (Fig. 5C) increased gradually throughout fruit development. In general, glucose and fructose increased within each genotype only at 60 DAA, while sucrose increased significantly at all time points. At 20 DAA glucose and sucrose were 
virtually invariant between genotypes, whereas fructose was reduced in gib3. At 40 DAA we observed reductions only in sucrose in fruits from gib3 plants. Surprisingly, fruits from the same genotype displayed values significantly higher in relation to the WT for most sugars evaluated at 60 DAA. Unlike soluble sugars, the levels of starch were altered in the genotypes throughout the fruit development (Fig. 5D). Between 20 and 40 DAA significant increases in starch content were observed reaching the highest observed values during fruit development. After the 40 DAA, the starch levels reduced in both WT and gib3 fruits. At 60 DAA the WT fruits presented starch levels similar to at 20 DAA, while in the gib3 fruits these levels were lower than 20 DAA. The pattern observed for starch is compatible with those found in sugar, characterizing the conversion of the carbohydrate reserve, starch, into sugar as the ripening occurs. No differences were observed for starch when comparing the genotypes at each time points. The content of the organic acids malate (Fig. 5E) and fumarate (Fig. 5F) was not affected by the reduction of the endogenous level of GAs, except for fumarate at 60 DAA. Both metabolites displayed gradual increments of their content throughout fruit development. Fumarate differed significantly between all periods, while malate differed only between the last two stages of the development.

To further explore the consequences of the reduced GA biosynthesis on primary metabolism during fruit development we extended the analyses by studying the major primary metabolic pathways, by using an established gas chromatography mass spectrometry (GCMS) approach. These analyses revealed that among over 50 successfully annotated compounds related to primary metabolism, considerable changes occurred in the levels of a wide range of amino acids, organic acids, and sugars (Fig. 6 and

Supplementary Fig. 5). In general, higher variations in amino acid levels between genotypes or throughout fruit development within each genotype were verified at 40 and 60 DAA. In other groups of metabolites, the variations occurred mainly at 60 DAA. For sake of simplicity, the metabolites highlighted in Fig. 6 are either directly derived or feed the glycolytic pathway and the tricarboxylic acid (TCA) cycle, both processes involved with cell energetic metabolism. Surprisingly, the metabolite profiles of the gib3 mutant line followed a similar pattern to those of the WT. Thus, the levels of sucrose, glucose-6P and fructose-6P did not present large variations either between genotypes or along the fruit development.

Similar behaviour was observed for organic acids and as such significant increases were verified during fruit ripening for malate and especially for 2-oxoglutarate. Malate is further converted to oxaloacetate, which, together with 2-oxoglutarate, are points of diversion/deviation of TCA cycle intermediates for the biosynthetic pathway of various amino acids (Lancien et al. 2000). Regarding the oxaloacetate-derived amino acids, we were not able to detect lysine and methionine. Although asparagine, homoserine, aspartate and threonine did not differ between genotypes at $20 \mathrm{DAA}$, reductions in isoleucine were observed in gib3 fruits at this time point. The levels of isoleucine, homoserine and asparagine reduced at 40 DAA whereas at 60 DAA only threonine reduced in gib3 fruits. During ripening aspartate, asparagine and threonine showed, in general, significant increases in both genotypes, while homoserine and isoleucine were virtually invariant. From the 2-oxoglutarate, another point of diversion of the TCA cycle six amino acids were detected including histidine, glutamine, glutamate, proline, ornithine, hydroxyproline, and GABA. Although none of them displayed differences between the genotypes at 20 DAA, significant reductions in histidine and glutamine were observed in gib3 fruits at 40 DAA. Fruits from gib3 mutant 
plants were characterized by reductions in proline, hydroxyproline and ornithine during ripening, whereas GABA reduced only at $60 \mathrm{DAA}$. By analysing these compounds during ripening for each genotype, it is possible to verify that the great majority exhibited gradual and significant increments during fruit developed. It is worth mentioning that these compounds reflected well the behaviour found in 2oxoglutarate. Similar behaviour to the compounds derived from 2-oxoglutarate was also verified for cysteine, serine and glycine, which are all derived from 3P-glycerate. Not only the amino acids valine, leucine and alanine, which are synthesized from pyruvate, but also phenylalanine and tyrosine, presented lower contents during all development in both genotypes, with significant reduction in the three stages just for leucine. The levels of tryptophan were distinct between WT and gib3 fruits at 40 and 60 DAA, and a gradual increment was observed from 40 to 60 DAA in WT fruits. For tyramine there was similar content for both genotypes at 40 and 60 DAA whereas at 20 DAA we were unable to identify this metabolite for gib3 fruits. Similarly, to tryptophan, an increased content of tyramine was observed at 60 DAA.

Although relatively few morphological or metabolic disturbances have been observed between genotypes during fruit development, it seems reasonable to suggest that the changes observed in 2-oxoglutarate, the substrate of the 2-oxoglutarate dehydrogenase that also generates the reduced coenzyme NADH, may also affect the redox balance. Therefore, we decided to assay the levels of pyridine dinucleotide during fruit ripening in WT and gib3 plants. Surprisingly, however, alterations in neither pyridine nucleotide level per se nor in the NADH/NAD and NADPH/NADP ratios were observed between genotypes across fruit ripening (Supplementary Fig. 6).

\section{Discussion}

The effects of the manipulation on the endogenous levels of GAs on plant growth have been previously described (Strader et al. 2004; Wuddineh et al. 2015; Zhang et al. 2016). To date, the morphological and biochemical mechanisms underlying the plant response to fluctuations in the levels of GAs during fruit development are not yet defined. Here, we decided to explore the influence of changes in the endogenous levels of GAs during reproductive phase in tomato fruits. This approach has revealed novel insights into the links between GA-related fertilization in tomato and yield together with a range of associated metabolic changes. It has been previously shown that GAs are directly involved in plant growth and development including flowering and fruit development (Olszewski et al. 2002; Gao et al. 2012; Andrés et al. 2014). Moreover, GAs regulate floral development and play an important role in male and female fertility (Griffiths et al. 2006; Pimenta Lange et al. 2012; Pimenta Lange and Lange, 2016). Thus, the compromised reproductive development observed in gib2 and gib1 mutants (mildly and extremely deficient in the biosynthesis of GAs, respectively), completely differing from the mutant genotype gib3 (moderately deficient in GA biosynthesis) and WT (Fig. 1), is likely explained by the reduced content of GA4 and GA7 in both genotypes, as well as the reduction of GA9, a precursor of GA4, in gib1 mutant plants (Supplementary Fig. 2), a mutant whose phenotype is more drastic. Thus, gib2 and gib1 mutants had their development restricted to the flower bud stage as previously verified (Nester and Zeevaart, 1988; Jacobsen and Olszewski, 1991). Similar changes were also observed previously in rice (Oriza sativa L. cv Nipponbare) overexpressing the enzyme GA2ox (Sakamoto et al. 2001), as well as in Arabidopsis, 
petunia, and tobacco that overexpressed GAMT1 (Varbanova et al. 2007), in good agreement with the need of adequate GAs levels for the complete flower development (Groot et al. 1987; Van den Heuvel et al. 2002). Despite the fact that the anther development in gib2 and gib1 was retained just prior to meiosis, 75 to $90 \%$ of this phenotype can be reversed by exogenous application of bioactive GAs at concentrations higher than $50 \mathrm{ng}$ per bud (Nester and Zeevaart, 1988; Shinozaki et al. 2015). Moreover, all gib mutants used here are typical GA-responsive mutants since all aspects of the mutants such as reduced plant height, leaf size and flower morphology can be reversed to WT by GA application (Koornneef et al. 1990; Asahina et al. 2002). Although gib3 mutant plants (moderately deficient in the biosynthesis in GAs) were characterized by minor morphological differences, at inflorescence level, in relation to its WT counterpart (Fig. 2A and B), the endogenous reduction of GAs was not able to affect both the final phenotype and fruit production (Supplementary Fig. 3 and Fig. 4). Likewise, the results described here are in good agreement with not only with the reduction observed only for the content of GA7 (Supplementary Fig. 2) but also with those previously observed for the same genotypes when only the vegetative stage was evaluated (Martins et al. 2019; Omena-Garcia et al. 2019). By contrast, both GA20ox overexpressing plants and the procera mutant in tomato showed numerous variations in floral organs coupled with higher number of fruits per plant and a reduced fruit size (Olszewski et al. 2002; Carrera et al. 2012; Nir et al. 2017). It seems reasonable to assume that this smaller fruit size was likely triggered by differences in source-sink strength. It is also worth noting that the final size of a fruit, in addition to the genotype, can be influenced by the position it occupies in the plant stem, climatic conditions and cultural practices to which the plants are subjected (Srivastava and Handa, 2005). It is equally important to mention that a tight fine-tuning between auxin and GA signalling ( $\mathrm{Hu}$ et al. 2018) as well as a crosstalk between GAs and two unrelated miRNAs (Silva et al. 2019) are seemingly essential for controlling the switch from flower into fruit development in tomato. Moreover, overexpression and loss-offunction of PROCERA, a single tomato DELLA protein, culminated in significant changes in growth, flowering, fruit development, and transpiration (Livne et al. 2015; Nir et al. 2017). Therefore, future genetic studies are clearly required to fully achieve mechanistic understanding of the role of GAS in tomato floral transition and inflorescence development.

Developmental stages of tomato fruits can be divided in time specific steps defined as: (i) floral development and fruit set; (ii) growth characterized by cell division and expansion; (iii) maturation; and (iv) ripening/senescence (Gillaspy et al. 1993; Srivastava and Handa, 2005; Obroucheva, 2014; Shinozaki et al. 2015). It is known that GAs are involved in cell division (Lammens et al. 2008; Sablowski and Carnier Dornelas, 2014), and cell expansion process (Bouquin, 2003; Band et al. 2012) and as such our analyses were carried out at different stages of fruit development. For all morphological parameters (size, diameter, fresh and dry weight, volume) reduced values were observed for gib3 fruits with 20 and 40 DAA (Fig. 3A-D and 3F); however, at 60 DAA these differences were no longer found suggesting, thus, that the reduction of GAs only promoted a delay in early growth and development of the mutant fruits. These results corroborate with the model previously suggested by (Srivastava and Handa, 2005), in which GA reaches maximum levels during fruit formation mainly between 7 to 15 DAA and 3 to 5 weeks after anthesis. Remarkably, this time match exactly with cell division and cellular expansion phases. 
The impacts of GAs on primary metabolism has been also previously demonstrated (Araújo et al. 2012a; Ribeiro et al. 2012a; Andrés et al. 2014; Nir et al. 2014), although this relationship still remains unclear. Among metabolic changes occurring throughout fruit development the differential accumulation of pigments is visually perceptible (Carrari et al. 2006). The greenish tint of the fruit became reddish across fruit ripening (Supplementary Fig. 4). This fact is represented by the reduction of chlorophyll contents (Fig. 4A and B) and consequent carotenoids accumulation (Fig. 4C) that clearly differed between genotypes from 40 DAA being always higher in gib3 fruits. The presence of little, if any, difference between genotypes when we evaluated the amino acid contents (Fig. 4E), proteins (Fig. 4F) and the organic acids malate (Fig. 5E) and fumarate (Fig. 5F), probably reflect the minor influence of GAs on these metabolites during fruit development. Here, the changes observed occurred mainly at 60 DAA and may be a direct consequence of the natural ripening process (Carrari and Fernie, 2006; Araújo et al. $2012 b$ ), that seems to not be affected by relatively small reductions in the levels of GAs. By analysing the contents of soluble sugars little difference was found between WT and gib3 fruits, although the contents clearly increase in fruits of both genotypes during ripening (Fig. 5A, B and C). They increased in an essentially linear manner reaching maximum values at $60 \mathrm{DAA}$, which is consistent with results observed for glucose and fructose in tomato fruits previously (Carrari et al. 2006). In addition, the changes observed in soluble sugars content largely justifies the starch levels (Fig. 5D), that increased until 40 DAA and decreased in fruits at 60 DAA, when we observed increases in the soluble sugars levels. This increase on sugars content and decrease on starch between 40 to 60 DAA, however, was similar to that found in tomato fruits at 35 and 65 DAA of plants with low expression of the mitochondrial fumarase (Centeno et al. 2011).Perhaps more importantly, this inversion in the content of carbohydrate reserves as well as other metabolites during the fruit ripening process culminates in organoleptic and desirable quality characteristics such as texture, colour, taste and flavour (Srivastava and Handa, 2005; Zhang et al. 2015; Qin et al. 2016). When considered together, these results coupled with the relatively minor changes in fruit set and fruit growth suggest that GA levels is important per se for normal fruit development and performance. However, it is highly interesting that, despite the dramatic changes in leaf metabolism and plant development observed when GA levels are strongly reduced, relatively minor changes in GA levels, as in gib3 mutant plants (Bensen and Zeevaart, 1990), do not strongly impact fruit set, yield, and germination rates, suggesting the presence of sophisticated signaling mechanisms by which the plant uses the senescence process to prioritize the supply of nutrients to sustain reproductive tissues.

The alterations observed between fruits of WT and gib3 mutant plant cannot be directly explained by the influence of GAs in the process of this organ development, at least on late stages, where the alterations look like as common change between semi autotrophic and heterotrophic metabolisms. Therefore, it was decided to follow the repertoire of metabolic changes that occur during fruit development. Large changes in the levels of amino acids were verified between genotypes and throughout fruit development, especially at 40 and 60 DAA (Fig. 6). Largest increases were observed in amino acids derived from oxaloacetate, 3P-glycerate and 2-oxoglutarate, and importantly these results are consistent with previously described results (Carrari and Fernie, 2006; Araújo et al. 2012b). Besides its direct involvement in amino acid metabolism, 2-oxoglutarate is also involved in the metabolism of several metabolites 
including flavonoids, glucosinolate, alkaloids, coumarins and Gas (Araújo et al. 2014). Enzymes involved in the final stages of both synthesis and degradation of GAs (GA3ox, GA20ox and GA2ox, respectively) are part of the large 2-oxoglutarate dependent dioxygenases family (Hedden and Phillips, 2000). Notably, the relationship between 2-oxoglutarate and GAs metabolism was previously demonstrated in tomato plants with reduced 2-oxoglutarate dehydrogenase (OGDH) activity. These plants displayed reductions in the transcript levels of the GA2ox4 and GA3ox3 and consequently in the GA3 content, one of the bioactive form of Gas (Araújo et al. 2012b). Our results aid further evidence in the connection between primary metabolism, mediated by changes in 2-oxoglutarate, and GAs metabolism supporting the growing body of evidence associated with a significant network behaviour in the coordination of amino acid metabolism (Galili, 2011; Galili et al. 2014; Hildebrandt et al. 2015).

Increases in the contents of the amino acids histidine, proline, hydroxyproline, ornithine and glutamine are consistent with the observed increase in glutamate, from which they all derive. Increments on the levels of glutamate during fruit ripening is of pivotal significance during this process (Grierson, 1992), since it is a direct precursor of the biosynthetic pathway of chlorophyll (Carrari et al. 2006; Szafranska et al. 2017). Accordingly, chlorophylls are usually present at very low concentration or even absent in mature fruits (Carrari et al. 2006). This reduction occurs due to the degradation of chlorophylls and carotenoids (Ye et al. 2015), characteristic of the conversion of chloroplasts to chromoplasts during fruit ripening which is visually perceived by colour transitions (Bartley et al. 1994; Kahlau and Bock, 2008). Changes in sugar metabolism and its effects on fruit ripening have been previously demonstrated, although the exact mechanism associated with sugar has not yet been fully elucidated (Qin et al. 2016). Carbohydrates are the most abundant compounds on soluble solids of ripe tomato fruits, where the content of glucose, fructose and sucrose are mainly used as indicators of quality (Baxter et al. 2005; Zhang et al. 2015). Increases in soluble sugars were observed in fruits of both genotypes during fruit ripening, ranging from 40 to $70 \%$ between 40 and 60 DAA. High sucrose levels were also observed in ripe peach fruits (Vimolmangkang et al. 2016) and berry (Tilbrook and Tyerman, 2009). As such, it is important to mention that different processes can contribute to the increase of soluble sugars in fruits (Dai et al. 2016) including first the import of photoassimilates from leaves via phloem, sucrose being the main sugar transported in higher plants (Braun and Slewinski, 2009; Kühn and Grof, 2010). It is worth to notice that this process follows different patterns and mechanism of unloading according to the species (Ruan and Patrick, 1995; Lalonde et al. 2003; Kühn and Grof, 2010; Biais et al. 2014; Zhang et al. 2015). Secondly, the metabolism of imported compounds into different cell compartments (apoplasm, symplasm and/or vacuole) to synthesize organic acids, cell walls and storage compounds, such as starch. Thirdly, dilution which may change the concentration without, however, altering the amount of the metabolite and is dependent on the environmental conditions (Genard et al. 2014; Dai et al. 2016). Notably, a close relationship was verified here between the increase of the concentration of soluble sugars and the degradation of the starch between the 40 and 60 DAA. It should be noticed that tomato fruit breeding has been largely oriented, through processes of improvement, to sugar content higher than $60 \%$ of the dry weight (Yelle et al. 1988; Carrari and Fernie, 2006). Although the precise nature of the interaction between 
energy and sugar metabolism coupled with the GA-mediated regulation of fruit growth and development could not be fully resolved in this study, it clearly remains an exciting topic for future research.

\section{Conclusions}

We investigated the role played by GAs during the transition process from vegetative to reproductive phase and during the reproductive organs development. The function of GAs in the maintenance of the flowering process was very clear in gib2 and gib1 mutant plants. Reductions in the endogenous content of bioactive GAs observed in those mutant plants was associated with a significant restriction in their development at floral bud phase. We also found that fruits of gib3 plants showed little difference from WT fruits. Surprisingly, the morphological variations that were observed in young fruits were not sustained during fruit development with the phenotype being fully recovered in red ripe fruits. Our result indicates that the reduced GAs content verified in gib3 mutant promotes only a delay in fruit development which is in good agreement with the action of this hormone being solely reported in the early stages of fruit development. The metabolic changes observed between genotypes started mainly at $40 \mathrm{DAA}$, and this is the phase characterized by the natural fruit ripening and in which there are no reports of the presence and/or action of GAs. Thus, we here present compelling evidence for a significant function of GA in governing early fruit set and development despite minor metabolic changes during later stages of fruit ripening. Although the absence of alterations in fruit yield and seed production despite reductions in the levels of GAs is somewhat surprising it is tempting to speculate that pathways of energy metabolism and hormone metabolism and transport are most likely highly interconnected at the whole-plant level in a manner that allows the plant to prioritize reproductive organs during plant senescence. It will be important to establish the functional significance of this observation in future studies in order to fully understand the molecular regulatory hierarchy regulating GA balance at the whole-plant level.

\section{Declarations}

\section{Author contributions:}

AOM, AN-N, DMR and WLA designed the research; AOM performed most of the research with the support of WAS, FSO and RPO-G; JGV and SO performed gibberellin analysis; JGV, SO ARF, AN-N, and DMR analysed the data, discussed the results and complemented the writing; AOM, and WLA analysed the data and wrote the article which was later approved by the all the others.

Funding: This work was supported by funding from the Max-Planck Society (to ANN and WLA), the Conselho Nacional de Desenvolvimento Científico e Tecnológico (CNPq-Brazil, Grant 306355/2012-4 to ANN and Grant 402511/2016-6 to WLA), the the Fundação de Amparo à Pesquisa do Estado de Minas Gerais (FAPEMIG-Brazil, Grant APQ-01357-14, and RED-00053-16). Research fellowships granted by CNPq-Brazil to A.N.N. and W.L.A. and scholarship provided by CNPq to AOM and the Coordenação de Aperfeiçoamento de Pessoal de Nível Superior (CAPES-Brazil) to RPO-G are also gratefully acknowledged. 


\section{Conflict of interest}

The authors declare that there is no conflict of interest regarding the publication of this article.

\section{References}

1. Achard P, Gusti A, Cheminant S, Alioua M, Dhondt S, Coppens F, Beemster GTS, Genschik P (2009) Gibberellin signaling controls cell proliferation rate in Arabidopsis. Curr Biol 19: 1188-1193. https://doi.org/10.1016/j.cub.2009.05.059

2. Andrés F, Porri A, Torti S, Mateos J, Romera-Branchat M, García-Martínez JL, Fornara F, Gregis V, Kater MM, Coupland G (2014) SHORT VEGETATIVE PHASE reduces gibberellin biosynthesis at the Arabidopsis shoot apex to regulate the floral transition. Proc Natl Acad Sci 111: E2760-E2769. https://doi.org/10.1073/pnas.1409567111

3. Araújo WL, Martins AO, Fernie AR, Tohge T (2014) 2-Oxoglutarate: linking TCA cycle function with amino acid, glucosinolate, flavonoid, alkaloid, and gibberellin biosynthesis. Front Plant Sci 5: 1-6. https://doi.org/10.3389/fpls.2014.00552

4. Araújo WL, Nunes-Nesi A, Nikoloski Z, Sweetlove LJ, Fernie AR (2012a) Metabolic control and regulation of the tricarboxylic acid cycle in photosynthetic and heterotrophic plant tissues. Plant Cell Environ 35: 1-21. https://doi.org/10.1111/j.1365-3040.2011.02332.x

5. Araújo WL, Tohge T, Osorio S, Lohse M, Balbo I, Krahnert I, Sienkiewicz-Porzucek A, Usadel B, NunesNesi A, Fernie AR (2012b) Antisense inhibition of the 2-oxoglutarate dehydrogenase complex in tomato demonstrates its importance for plant respiration and during leaf senescence and fruit maturation. Plant Cell 24: 2328-2351. https://doi.org/10.1105/tpc.112.099002

6. Asahina M, Iwai H, Kikuchi A, Yamaguchi S, Kamiya Y, Kamada H, Satoh S (2002) Gibberellin produced in the cotyledon is required for cell division during tissue reunion in the cortex of cut cucumber and tomato hypocotyls. Plant Physiol 129: 201-210. https://doi.org/10.1104/pp.010886

7. Aya K, Ueguchi-Tanaka M, Kondo M, Hamada K, Yano K, Nishimura M, Matsuoka M (2009) Gibberellin modulates anther development in rice via the transcriptional regulation of GAMYB. Plant Cell Online 21: 1453-1472. https://doi.org/10.1105/tpc.108.062935

8. Band LR, Ubeda-Tomas S, Dyson RJ, Middleton AM, Hodgman TC, Owen MR, Jensen OE, Bennett MJ, King JR (2012) Growth-induced hormone dilution can explain the dynamics of plant root cell elongation. Proc Natl Acad Sci 109: 7577-7582. https://doi.org/10.1073/pnas.1113632109

9. Bartley GE, Scolnik PA, Giuliano G (1994) Molecular biology of carotenoid biosynthesis in plants. Ann Rev Plant Physiol Plant Mol Biol 45: 287 -301.

https://doi.org/10.1146/annurev.pp.45.060194.001443

10. Batista-Silva W, Nascimento VL, Medeiros DB, Nunes-Nesi A, Ribeiro DM, Zsögön A, Araújo WL (2018) Modifications in organic acid profiles during fruit development and ripening: Correlation or causation? Front Plant Sci. 9, 1689. https://doi.org/10.3389/fpls.2018.01689 
11. Baxter CJ, Carrari F, Bauke A, Overy S, Hill SA, Quick PW, Fernie AR, Sweetlove LJ (2005) Fruit carbohydrate metabolism in an introgression line of tomato with increased fruit soluble solids. Plant Cell Physiol 46: 425-437. https://doi.org/10.1093/pcp/pci040

12. Bensen RJ, Zeevaart JAD (1990) Comparison of ent-kaurene synthetase A and B activities in cell-free extracts from young tomato fruits of Wild-Type and gib-1, gib-2, and gib-3 tomato plants. J Plant Growth Regul 9: 237-242. https://doi.org/10.1007/BF02041969

13. Bernier G, Périlleux C (2005) A physiological overview of the genetics of flowering time control. Plant Biotechnol J 3: 3-16. https://doi.org/10.1111/j.1467-7652.2004.00114.x

14. Biais B, Benard C, Beauvoit B, Colombie S, Prodhomme D, Menard G, Bernillon S, Gehl B, Gautier H, Ballias $P$, et al (2014) Remarkable reproducibility of enzyme activity profiles in tomato fruits grown under contrasting environments provides a roadmap for studies of fruit metabolism. Plant Physiol 164: 1204-1221. https://doi.org/10.1104/pp.113.231241

15. Bouché F, Woods DP, Amasino RM (2017) Winter memory throughout the plant kingdom: different paths to flowering. Plant Physiol 173: 27-35. https://doi.org/10.1104/pp.16.01322

16. Bouquin T (2003) The Arabidopsis lue1 mutant defines a katanin p60 ortholog involved in hormonal control of microtubule orientation during cell growth. J Cell Sci 116: 791-801. https://doi.org/10.1242/jcs.00274

17. Bradford MM, Dong Y, Xu L, Liu S, Bai X, Bradford M, Briskin D, Leonard R, Hodges T, Buchanan B, et al (1976) A rapid and sensitive method for the quantitation of microgram quantities of protein utilizing the principle of protein-dye binding. Anal Biochem 72: 248-254. https://doi.org/10.1016/0003-2697(76)90527-3

18. Braun DM, Slewinski TL (2009) Genetic control of carbon partitioning in grasses: roles of sucrose transporters and tie-dyed loci in phloem loading. Plant Physiol 149: 71-81. https://doi.org/10.1104/pp.108.129049

19. Carrari F, Baxter C, Usadel B, Urbanczyk-Wochniak E, Zanor M-I, Nunes-Nesi A, Nikiforova V, Centero D, Ratzka A, Pauly M, et al (2006) Integrated analysis of metabolite and transcript levels reveals the metabolic shifts that underlie tomato fruit development and highlight regulatory aspects of metabolic network behavior. Plant Physiol 142: 1380-1396. https://doi.org/10.1104/pp.106.088534

20. Carrari F, Fernie AR (2006) Metabolic regulation underlying tomato fruit development. J Exp Bot 57: 1883-1897. https://doi.org/10.1093/jxb/erj020

21. Carrera E, Ruiz-Rivero O, Peres LEP, Atares A, Garcia-Martinez JL (2012) Characterization of the procera tomato mutant shows novel functions of the SIDELLA protein in the control of flower morphology, cell division and expansion, and the auxin-signaling pathway during fruit-set and development. Plant Physiol 160: 1581-1596.https://doi.org/10.1104/pp.112.204552

22. Centeno DC, Osorio S, Nunes-Nesi A, Bertolo ALF, Carneiro RT, Araújo WL, Steinhauser M-C, Michalska J, Rohrmann J, Geigenberger P, et al (2011) Malate plays a crucial role in starch metabolism, ripening, and soluble solid content of tomato fruit and affects postharvest softening. Plant Cell 23: 162-184. https://doi.org/10.1105/tpc.109.072231 
23. Chiwocha SDS, Abrams SR, Ambrose SJ, Cutler AJ, Loewen M, Ross ARS, Kermode AR (2003) A method for profiling classes of plant hormones and their metabolites using liquid chromatographyelectrospray ionization tandem massspectrometry: an analysis of hormone regulation of thermodormancy of lettuce (Lactuca sativa L.) seeds. Plant J 35: 405-417. https://doi.org/10.1046/j.1365-313X.2003.01800.x

24. Chhun T, Aya K, Asano K, Yamamoto E, Morinaka Y, Watanabe M, Kitano H, Ashikari M, Matsuoka M, Ueguchi-Tanaka M (2007) Gibberellin regulates pollen viability and pollen tube growth in rice. Plant Cell 19: 3876-3888. https://www.jstor.org/stable/20077250

25. Claeys H, Skirycz A, Maleux K, Inze D (2012) DELLA signaling mediates stress-induced cell differentiation in Arabidopsis leaves through modulation of anaphase-promoting complex/Cyclosome activity. Plant Physiol 159: 739-747. https://doi.org/10.1104/pp.112.195032

26. Cross JM, von Korff M, Altmann T, Bartzetko L, Sulpice R, Gibon Y, Palacios N, Stitt M (2006) Variation of enzyme activities and metabolite levels in 24 Arabidopsis accessions growing in carbonlimited conditions. Plant Physiol 142: 1574-1588. https://doi.org/10.1104/pp.106.086629

27. Dai Z, Wu H, Baldazzi V, van Leeuwen C, Bertin N, Gautier H, Wu B, Duchêne E, Gomès E, Delrot S, et al (2016) Inter-species comparative analysis of components of soluble sugar concentration in fleshy fruits. Front Plant Sci 7: 1-12. https://doi.org/10.3389/fpls.2016.00649

28. Dorcey E, Urbez C, Blázquez MA, Carbonell J, Perez-Amador MA (2009) Fertilization-dependent auxin response in ovules triggers fruit development through the modulation of gibberellin metabolism in Arabidopsis. Plant J 58: 318-332. https://doi.org/10.1111/j.1365-313X.2008.03781.x

29. Fernie AR, Roscher A, Ratcliffe RG, Kruger NJ (2001) Fructose 2,6-bisphosphate activates pyrophosphate: Fructose-6-phosphate 1-phosphotransferase and increases triose phosphate to hexose phosphate cycling heterotrophic cells. Planta 212: 250-263.

https://doi.org/10.1007/s004250000386

30. Fos M, Proaño K, Nuez F, García-Martínez JL (2001) Role of gibberellins in parthenocarpic fruit development induced by the genetic system pat-3/pat-4 in tomato. Physiol Plant 111: 545-550. https://doi.org/10.1034/j.1399-3054.2001.1110416.x

31. Galili G (2011) The aspartate-family pathway of plants: linking production of essential amino acids with energy and stress regulation. Plant Signal Behav 6: 192-195. https://doi.org/10.4161/psb.6.2.14425

32. Galili G, Avin-Wittenberg T, Angelovici R, Fernie AR (2014) The role of photosynthesis and amino acid metabolism in the energy status during seed development. Front Plant Sci 5: 1-7. https://doi.org/10.3389/fpls.2014.00447

33. Galvão VC, Collani S, Horrer D, Schmid M (2015) Gibberellic acid signaling is required for ambient temperature-mediated induction of flowering in Arabidopsis thaliana. Plant J 84: 949-962. https://doi.org/10.1111/tpj.13051

34. Gao Y, Chen J, Zhao Y, Li T, Wang M (2012) Molecular cloning and expression analysis of a RGA-like gene responsive to plant hormones in Brassica napus. Mol Biol Rep 39: 1957-1962. 
https://doi.org/10.1007/s11033-011-0943-7

35. Genard M, Baldazzi V, Gibon Y (2014) Metabolic studies in plant organs: don't forget dilution by growth. Front Plant Sci 5: 1-6. https://doi.org/10.3389/fpls.2014.00085

36. Gibon Y, Larher F (1997) Cycling assay for nicotinamide adenine dinucleotides: $\mathrm{NaCl}$ precipitation and ethanol solubilization of the reduced tetrazolium. Anal Biochem 251: 153-157. https://doi.org/10.1006/abio.1997.2283

37. Gillaspy G, Ben-david H, Gruissem W, Darwin C (1993) Fruits: a developmental perspective. Plant Cell 5: 1439-1451. https://doi.org/10.1105/tpc.5.10.1439

38. Gomez-Mena C (2005) Transcriptional program controlled by the floral homeotic gene AGAMOUS during early organogenesis. Development 132: 429-438. https://doi.org/10.1242/dev.01600

39. Grierson D (1992) Control of ethylene synthesis and ripening by sense and antisense genes in transgenic plants. Proc R Soc Edinburgh Sect B Biol Sci 99: 79-88. https://doi.org/10.1017/S0269727000005510

40. Griffiths J, Murase K, Rieu I, Zentella R, Zhang Z-L, Powers SJ, Gong F, Phillips AL, Hedden P, Sun T p., et al (2006) Genetic characterization and functional analysis of the GID1 gibberellin receptors in Arabidopsis. Plant Cell Online 18: 3399-3414. https://doi.org/10.1105/tpc.106.047415

41. Groot PC, Bniinsma J, Karssen CM (1987) The role of endogenous gibberellin in seed and fruit development of tomato: studies with a gibberellin-defident mutant. Physiol Plant 71: 184-190. https://doi.org/10.1111/j.1399-3054.1987.tb02865.x

42. Hanke S, Besir H, Oesterhelt D, Mann M (2008) Absolute SILAC for accurate quantitation of proteins in complex mixtures down to the attomole level. J Proteome Res 7: 1118-1130. https://doi.org/10.1021/pr7007175

43. Hedden P, Phillips AL (2000) Gibberellin metabolism: new insights revealed by the genes. Trends Plant Sci 5: 523-530. https://doi.org/10.1016/S1360-1385(00)01790-8

44. Van den Heuvel KJ, Van Lipzig RH, Barendse GW, Wullems GJ (2002) Regulation of expression of two novel flower-specific genes from tomato (Solanum lycopersicum) by gibberellin. J Exp Bot 53: 51-59. https://doi.org/10.1093/jexbot/53.366.51

45. Hildebrandt TM, Nunes Nesi A, Araújo WL, Braun HP (2015) Amino acid catabolism in plants. Mol Plant 8: 1563-1579. https://doi.org/10.1016/j.molp.2015.09.005

46. Hirano K, Ueguchi-Tanaka M, Matsuoka M (2008) GID1-mediated gibberellin signaling in plants. Trends Plant Sci 13: 192-199. https://doi.org/10.1016/j.tplants.2008.02.005

47. Hu J, Israeli A, Ori N, Sun TP (2018) The interaction between DELLA and ARF/IAA mediates crosstalk between gibberellin and auxin signaling to control fruit initiation in tomato. Plant Cell 30: 17101728. https://doi.org/10.1105/tpc. 18.00363

48. Hu L, Wu H, Qi Q, Li H, Li Z, Chen S, Ding Q, Wang Q, Yan Z, Gai Y, et al (2019) Gibberellins play a role in regulating tomato fruit ripening. Plant Cell Physiol 60: 1619-1629. https://doi.org/10.1093/pcp/pcz069 
49. Huang B, Qian P, Gao N, Shen J, Hou S (2017) Fackel interacts with gibberellic acid signaling and vernalization to mediate flowering in Arabidopsis. Planta 245: 939-950.

https://doi.org/10.1007/s00425-017-2652-5

50. Ireland HS, Yao JL, Tomes S, Sutherland PW, Nieuwenhuizen N, Gunaseelan K, Winz RA, David KM, Schaffer RJ (2013) Apple SEPALLATA1/2-like genes control fruit flesh development and ripening. Plant J 73: 1044-1056. https://doi.org/10.1111/tpj.12094

51. Jacobsen SE, Olszewski NE (1991) Characterization of the arrest in anther development associated with gibberellin deficiency of the gib-1 mutant of tomato. Plant Physiol 97: 409-414. https://doi.org/10.1104/pp.97.1.409

52. Kahlau S, Bock R (2008) Plastid transcriptomics and translatomics of tomato fruit development and chloroplast-to-chromoplast differentiation: chromoplast gene expression largely serves the production of a single protein. Plant Cell Online 20: 856-874.

https://doi.org/10.1105/tpc.107.055202

53. Klee HJ, Giovannoni JJ (2011) Genetics and control of tomato fruit ripening and quality attributes. Annu Rev Genet 45: 41-59. https://doi.org/10.1146/annurev-genet-110410-132507

54. Knapp S (2002) Tobacco to tomatoes: A phylogenetic perspective on fruit diversity in the Solanaceae. J Exp Bot 53: 2001-2022. https://doi.org/10.1093/jxb/erf068

55. Koornneef M, Bosma TDG, Hanhart CJ, Veen H Van Der, Zeevaart JAD (1990) The isolation and characterization of gibberellin-deficiens mutants in tomato. Theoret Appl Genetics 80: 852-857. https://doi.org/10.1007/BF00224204

56. Kopka J, Schauer N, Krueger S, Birkemeyer C, Usadel B, Bergmüller E, Dörmann P, Weckwerth W, Gibon Y, Stitt M, et al (2005) Systems biology GMD@CSB.DB: The Golm Metabolome Database. Bioinformatics 21: 1635-1638. https://doi.org/10.1093/bioinformatics/bti236

57. Kühn C, Grof CPL (2010) Sucrose transporters of higher plants. Curr Opin Plant Biol 13: 288-298. https://doi.org/10.1016/j.pbi.2010.02.001

58. Kwon CT, Kim SH, Kim D, Paek NC (2015) The rice floral repressor early flowering1 affects spikelet fertility by modulating gibberellin signaling. Rice 8: 1-11. https://doi.org/10.1186/s12284-015-00581

59. Lalonde S, Tegeder M, Throne-Holst M, Frommer WB, Patrick JW (2003) Phloem loading and unloading of sugars and aminoacids. Plant Cell Environ 26: 37-56. https://doi.org/10.1046/j.13653040.2003.00847.x

60. Lammens T, Boudolf V, Kheibarshekan L, Zalmas LP, Gaamouche T, Maes S, Vanstraelen M, Kondorosi E, La Thangue NB, Govaerts W, et al (2008) Atypical E2F activity restrains APC/CCCS52A2 function obligatory for endocycle onset. Proc Natl Acad Sci U S A 105: 14721-14726. https://doi.org/10.1073/pnas.0806510105

61. Lancien M, Gadal P, Hodges M (2000) Enzyme redundancy and the importance of 2-oxoglutarate in higher plant ammonium assimilation. Plant Physiol 123: 817-824.

https://doi.org/10.1104/pp.123.3.817

Page 20/31 
62. Lisec J, Schauer N, Kopka J, Willmitzer L, Fernie AR (2006) Gas chromatography mass spectrometrybased metabolite profiling in plants. Nat Protoc 1: 387-396. https://doi.org/10.1038/nprot.2006.59

63. Livne S, Lor VS, Nir I, Eliaz N, Aharoni A, Olszewski NE, Eshed Y, Weiss D (2015) Uncovering DELLAindependent gibberellin responses by characterizing new pomato procera mutants. Plant Cell 27: 1579-1594. https://doi.org/10.1105/tpc. 114.132795

64. Locascio A, Blázquez MA, Alabadí D (2013) Genomic analysis of della protein activity. Plant Cell Physiol 54: 1229-1237. https://doi.org/10.1093/pcp/pct082

65. Lytovchenko A, Eickmeier I, Pons C, Osorio S, Szecowka M, Lehmberg K, Arrivault S, Tohge T, Pineda B, Anton MT, et al (2011) Tomato fruit photosynthesis is seemingly unimportant in primary metabolism and ripening but plays a considerable role in seed development. Plant Physiol 157: 1650-1663. https://doi.org/10.1104/pp.111.186874

66. Mapelli S, Frova C, Torti G, Soressi GP (1978) Relationship between set, development and activities of growth regulators in tomato fruits. Plant Cell Physiol 19: 1281-1288.

https://doi.org/10.1093/oxfordjournals.pcp.a075709

67. Martins AO, Omena-Garcia RP, Oliveira FS, Silva WA, Hajirezaei MR, Vallarino JG, Ribeiro DM, Fernie AR, Nunes-Nesi A, Araújo WL (2019) Differential root and shoot responses in the metabolism of tomato plants exhibiting reduced levels of gibberellin. Environ Exp Bot 157: 331-343. https://doi.org/10.1016/j.envexpbot.2018.10.036

68. McAtee P, Karim S, Schaffer R, David K (2013) A dynamic interplay between phytohormones is required for fruit development, maturation, and ripening. Front Plant Sci 4: 1-7. https://doi.org/10.3389/fpls.2013.00079

69. Nester J., Zeevaart JA. (1988) Flower development in normal tomato and a gibberellin-deficient (ga2) mutant. Am J Bot 75: 45-55. https://doi.org/10.1002/j.1537-2197.1988.tb12160.x

70. Nir I, Moshelion M, Weiss D (2014) The Arabidopsis GIBBERELLIN METHYL TRANSFERASE 1 suppresses gibberellin activity, reduces whole-plant transpiration and promotes drought tolerance in transgenic tomato. Plant, Cell Environ 37: 113-123. https://doi.org/10.1111/pce.12135

71. Nir I, Shohat H, Panizel I, Olszewski NE, Aharoni A, Weiss D (2017) The tomato DELLA protein PROCERA acts in guard cells to promote stomatal closure. Plant Cell tpc.00542.2017. https://doi.org/10.1105/tpc. 17.00542

72. Nowaki RHD, Parent S-étienne, Filho ABC, Rozane DE, Meneses NB, Juliana A, Natale W (2017) Phosphorus over-fertilization and nutrient misbalance of irrigated tomato crops in Brazil. Plant Sci 8: 1-11. https://doi.org/10.3389/fpls.2017.00825

73. Nunes-Nesi A, Carrari F, Gibon Y, Sulpice R, Lytovchenko A, Fisahn J, Graham J, Ratcliffe RG, Sweetlove LJ, Fernie AR (2007) Deficiency of mitochondrial fumarase activity in tomato plants impairs photosynthesis via an effect on stomatal function. Plant J 50: 1093-1106. https://doi.org/10.1111/j.1365-313X.2007.03115.x

74. Obroucheva N V. (2014) Hormonal regulation during plant fruit development. Russ J Dev Biol 45: 1121. https://doi.org/10.1134/S1062360414010068 
75. Olimpieri I, Siligato F, Caccia R, Soressi GP, Mazzucato A, Mariotti L, Ceccarelli N (2007) Tomato fruit set driven by pollination or by the parthenocarpic fruit allele are mediated by transcriptionally regulated gibberellin biosynthesis. Planta 226: 877-888. https://doi.org/10.1007/s00425-007-0533Z

76. Olszewski N, Sun T-P, Gubler F (2002) Gibberellin signaling: biosynthesis, catabolism, and response pathways. Plant Cell 14 Suppl: S61-S80. https://doi.org/10.1105/tpc.010476

77. Omena-Garcia RP, Oliveira Martins A, Medeiros DB, Vallarino JG, Mendes Ribeiro D, Fernie AR, Araújo WL, Nunes-Nesi A (2019) Growth and metabolic adjustments in response to gibberellin deficiency in drought stressed tomato plants. Environ Exp Bot 159: 95-107.

https://doi.org/10.1016/j.envexpbot.2018.12.011

78. Pharis RP, King RW (1985) Gibberellins and reproductive development in seed plants. Plant Physiol 36: 517-568. https://doi.org/10.1146/annurev.pp.36.060185.002505

79. Pimenta Lange MJ, Knop N, Lange T (2012) Stamen-derived bioactive gibberellin is essential for male flower development of Cucurbita maxima L. J Exp Bot 63: 2681-2691.

https://doi.org/10.1093/jxb/err448

80. Pimenta Lange MJ, Lange T (2016) Ovary-derived precursor gibberellin A9 is essential for female flower development in cucumber. Development 143: 4425 LP - 4429.

https://doi.org/10.1242/dev.135947

81. Plackett ARG, Thomas SG, Wilson ZA, Hedden P (2011) Gibberellin control of stamen development: a fertile field. Trends Plant Sci 16: 568-578. https://doi.org/10.1016/j.tplants.2011.06.007

82. Qin G, Zhu Z, Wang W, Cai J, Chen Y, Li L, Tian S (2016) A tomato vacuolar invertase inhibitor mediates sucrose metabolism and influences fruit ripening. Plant Physiol 172: 1596-1611. https://doi.org/10.1104/pp.16.01269

83. Ribeiro DM, Araujo WL, Fernie AR, Schippers JHM, Mueller-Roeber B (2012a) Action of gibberellins on growth and metabolism of Arabidopsis plants associated with high concentration of carbon dioxide. Plant Physiol 160: 1781-1794. https://doi.org/10.1104/pp.112.204842

84. Ribeiro DM, Araújo WL, Fernie AR, Schippers JHM, Mueller-Roeber B (2012b) Translatome and metabolome effects triggered by gibberellins during rosette growth in Arabidopsis. J Exp Bot 63: 2769-2786. https://doi.org/10.1093/jxb/err463

85. Rieu I, Eriksson S, Powers SJ, Gong F, Griffiths J, Woolley L, Benlloch R, Nilsson O, Thomas SG, Hedden P, et al (2008) Genetic analysis reveals that C19-GA 2-oxidation is a major gibberellin inactivation pathway in Arabidopsis. Plant Cell Online 20: 2420-2436.

https://doi.org/10.1105/tpc. 108.058818

86. Ruan YL, Patrick JW (1995) The cellular pathway of postphloem sugar transport in developing tomato fruit. Planta An Int J Plant Biol 196: 434-444. https://doi.org/10.1007/BF00203641

87. Sablowski R, Carnier Dornelas M (2014) Interplay between cell growth and cell cycle in plants. J Exp Bot 65: 2703-2714. https://doi.org/10.1093/jxb/ert354 
88. Sakamoto T, Kobayashi M, Itoh H, Tagiri A, Kayano T, Tanaka H, Iwahori S, Matsuoka M (2001) Expression of a gibberellin 2-oxidase gene around the shoot apex is related to phase transition in rice. Plant Physiol 125: 1508-1516. https://doi.org/10.1104/pp.125.3.1508

89. Serrani JC, Fos $\mathbb{E}$ M, Atare $\mathbb{E}$ A, Garc L (2007a) Effect of gibberellin and auxin on parthenocarpic fruit growth induction in the cv Micro-Tom of tomato. J Plant Growth Regul 26: 211-221 (2007). https://doi.org/10.1007/s00344-007-9014-7

90. Serrani JC, Sanjuan R, Ruiz-Rivero O, Fos M, Garcia-Martinez JL (2007b) Gibberellin regulation of fruit set and growth in tomato. Plant Physiol 145: 246-257. https://doi.org/10.1104/pp.107.098335

91. Seymour GB, Granell A (2014) Fruit development and ripening. J Exp Bot 65: 4489-4490. https://doi.org/10.1093/jxb/eru307

92. Shinozaki Y, Ezura H, Ariizumi T (2016) The role of ethylene in the regulation of ovary senescence and fruit set in tomato (Solanum lycopersicum). Plant Signal Behav 2324: 00-00. https://doi.org/10.1080/15592324.2016.1146844

93. Shinozaki Y, Hao S, Kojima M, Sakakibara H, Ozeki-lida Y, Zheng Y, Fei Z, Zhong S, Giovannoni JJ, Rose JKC, et al (2015) Ethylene suppresses tomato (Solanum lycopersicum) fruit set through modification of gibberellin metabolism. Plant J 83: 237-251. https://doi.org/10.1111/tpj.12882

94. Silva GFF, Silva EM, Correa JPO, Vicente MH, Jiang N, Notini MM, Junior AC, De Jesus FA, Castilho P, Carrera E, et al (2019) Tomato floral induction and flower development are orchestrated by the interplay between gibberellin and two unrelated microRNA-controlled modules. New Phytol 221: 1328-1344. https://doi.org/10.1111/nph.15492

95. Srivastava A, Handa AK (2005) Hormonal regulation of tomato fruit development: a molecular perspective. J Plant Growth Regul 24: 67-82. https://doi.org/10.1007/s00344-005-0015-0

96. Strader LC, Ritchie S, Soule JD, McGinnis KM, Steber CM (2004) Recessive-interfering mutations in the gibberellin signaling gene SLEEPY1 are rescued by overexpression of its homologue, SNEEZY. Proc Natl Acad Sci U S A 101: 12771-12776. https://doi.org/10.1073/pnas.0404287101

97. Szafranska K, Reiter RJ, Posmyk MM (2017) Melatonin improves the photosynthetic apparatus in pea leaves stressed by paraquat via chlorophyll breakdown regulation and its accelerated de novo synthesis. Front Plant Sci 8: 1-10. https://doi.org/10.3389/fpls.2017.00878

98. Tilbrook J, Tyerman SD (2009) Hydraulic connection of grape berries to the vine: varietal differences in water conductance into and out of berries, and potential for backflow. Funct Plant Biol 36: 541550. https://doi.org/10.1071/FP09019

99. Varbanova M, Yamaguchi S, Yang Y, McKelvey K, Hanada A, Borochov R, Yu F, Jikumaru Y, Ross J, Cortes D, et al (2007) Methylation of gibberellins by Arabidopsis GAMT1 and GAMT2. Plant Cell Online 19: 32-45. https://doi.org/10.1105/tpc.106.044602

100. Vimolmangkang S, Zheng H, Peng Q, Jiang Q, Wang H, Fang T, Liao L, Wang L, He H, Han Y (2016) Assessment of sugar components and genes involved in the regulation of sucrose accumulation in peach fruit. J Agric Food Chem 64: 6723-6729. https://doi.org/10.1021/acs.jafc.6b02159 
101. Wellburn AR (1994) The spectral determination of chlorophylls $a$ and $b$, as well as total carotenoids, using various solvents with spectophotometers of different resolution. 307-313. https://doi.org/10.1016/S0176-1617(11)81192-2

102. Wuddineh WA, Mazarei M, Zhang J, Poovaiah CR, Mann DGJ, Ziebell A, Sykes RW, Davis MF, Udvardi MK, Stewart CN (2015) Identification and overexpression of gibberellin 2-oxidase (GA2ox) in switchgrass (Panicum virgatum $\mathrm{L}$.) for improved plant architecture and reduced biomass recalcitrance. Plant Biotechnol J 13: 636-647. https://doi.org/10.1111/pbi.12287

103. Ye J, Hu T, Yang C, Li H, Yang M, ljaz R, Ye Z, Zhang Y (2015) Transcriptome profiling of tomato fruit development reveals transcription factors associated with ascorbic acid, carotenoid and flavonoid biosynthesis. PLoS One 10: 1-25. https://doi.org/10.1371/journal.pone.0130885

104. Yelle S, Chetela RT, Dorais M, DeVerna JW, Bennett AB (1988) Sink metabolism in tomato fruit. Plant Physiol 87: 727-730. https://doi.org/10.1104/pp.87.3.727

105. Zhang C, Tateishi N, Tanabe K (2010) Pollen density on the stigma affects endogenous gibberellin metabolism, seed and fruit set, and fruit quality in Pyrus pyrifolia. J Exp Bot 61: 4291-4302. https://doi.org/10.1093/jxb/erq232

106. Zhang N, Jiang J, Yang Y, Wang Z (2015) Functional characterization of an invertase inhibitor gene involved in sucrose metabolism in tomato fruit. J Zhejiang Univ B 16: 845-856. https://doi.org/10.1631/jzus.B1400319

107. Zhang S, Zhang D, Fan S, Du L, Shen Y, Xing L, Li Y, Ma J, Han M (2016) Effect of exogenous GA3 and its inhibitor paclobutrazol on floral formation, endogenous hormones, and flowering-associated genes in 'Fuji' apple (Malus domestica Borkh.). Plant Physiol Biochem 107: 178-186. https://doi.org/10.1016/j.plaphy.2016.06.005

\section{Figures}




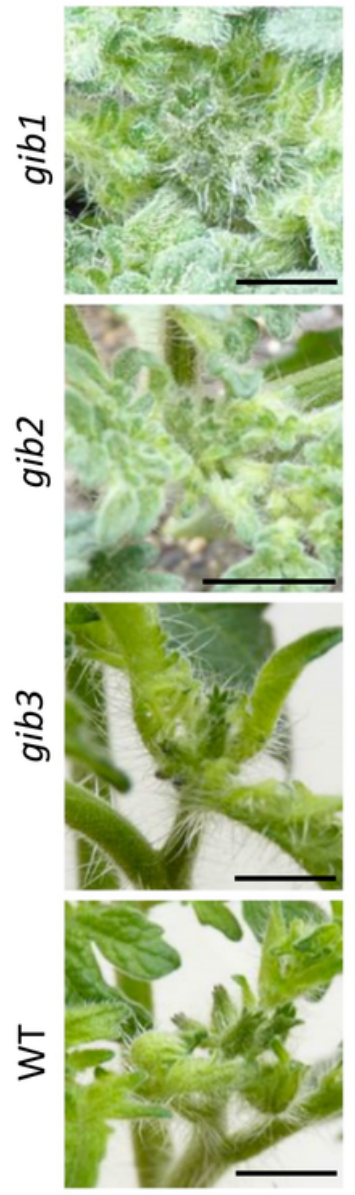

5
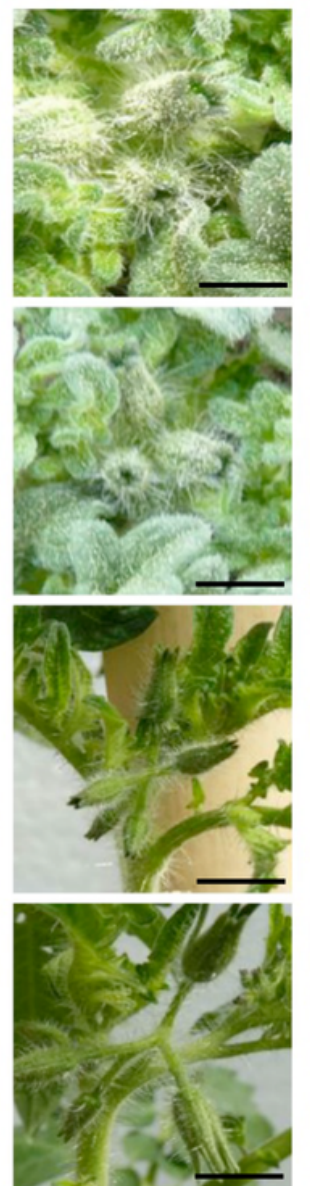

6
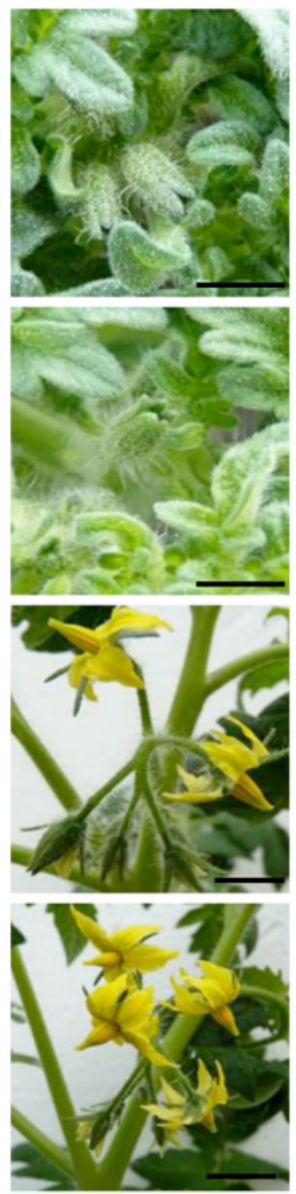

7
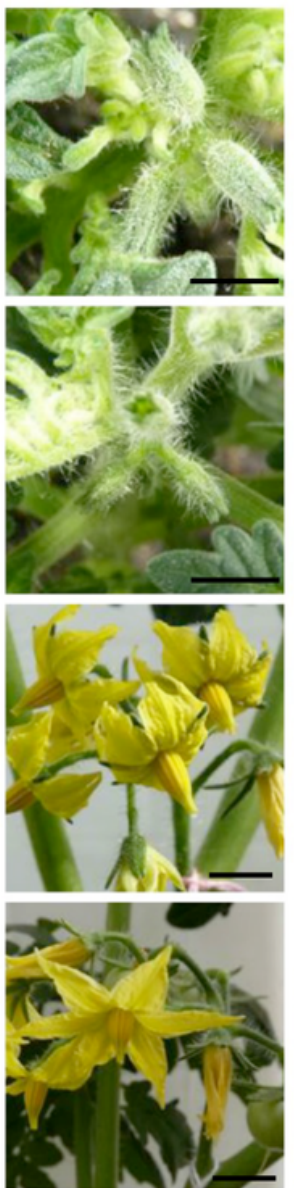

8
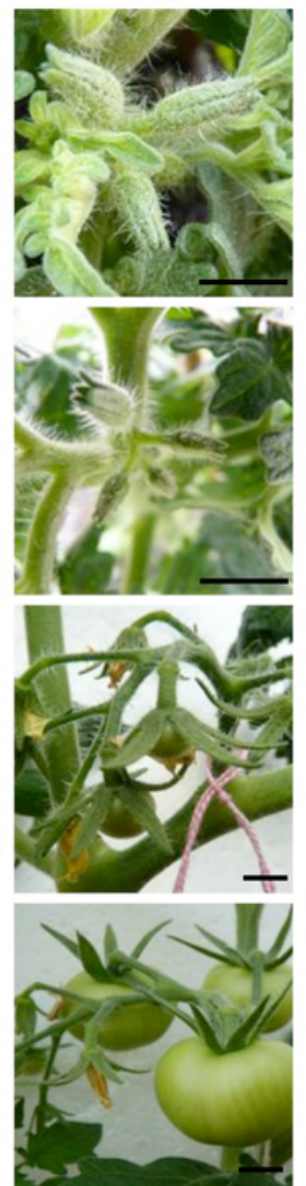

9
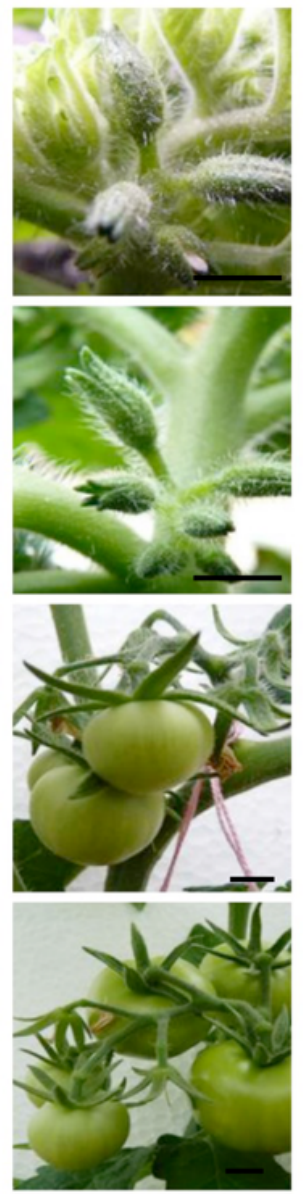

10

Weeks after transplant

\section{Figure 1}

Photographic record of the monitoring of inflorescence development in response to changes in gibberellins (GAs). The following genotypes were weekly monitored: WT (wild type) and mutants: gib3 (moderately deficient in GAs), gib2 (intermediate deficiency in GAs) and gib1 (extremely deficient in GAs). Scale: bars $=1 \mathrm{~cm}$ 

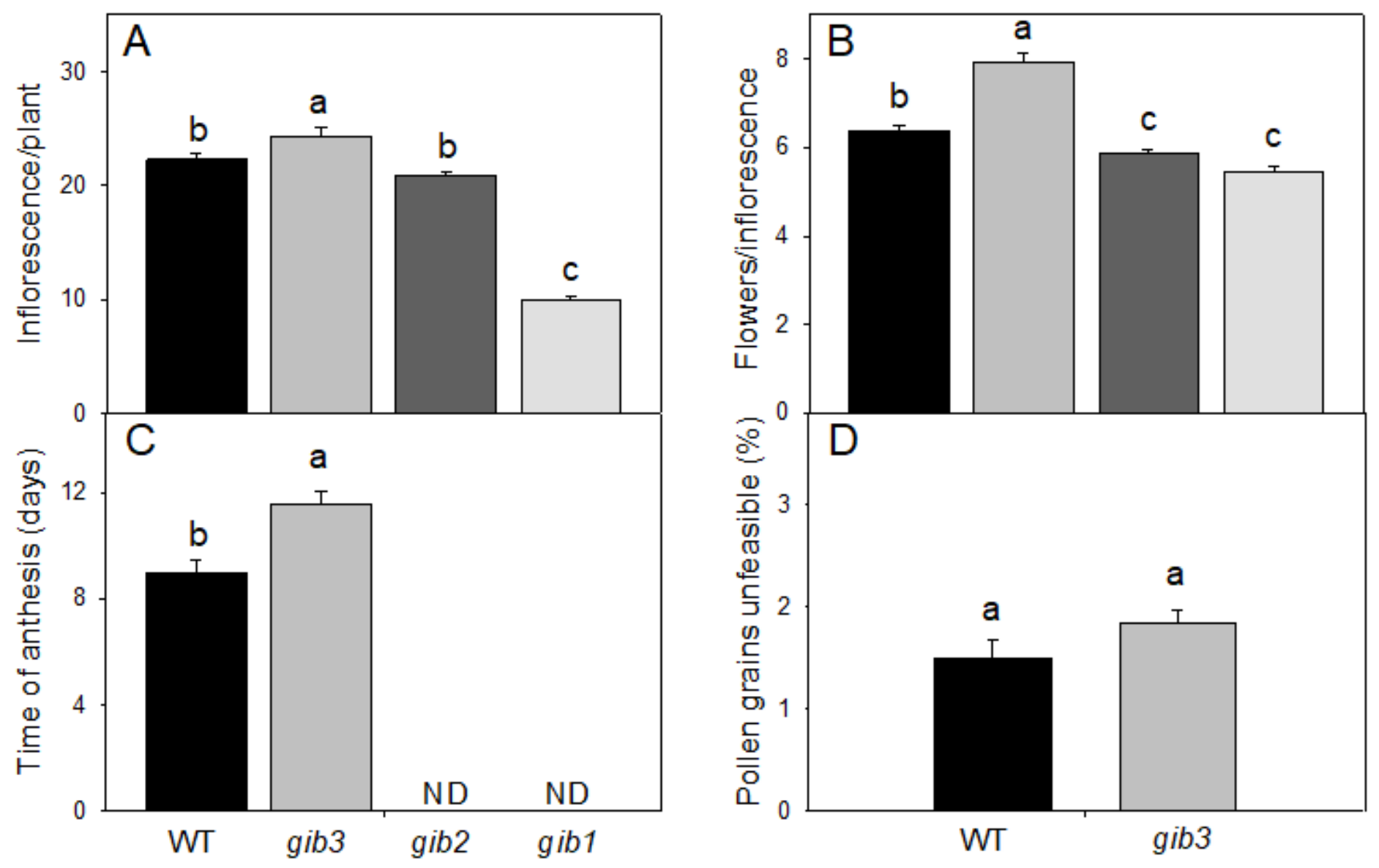

Figure 2

Variations on flowering development parameters in tomato plants in response to reduced endogenous of GA levels in WT and mutants plants deficient in the biosynthesis of gibberellins ( gib3, moderately deficient, gib2, intermediate deficiency and gib1, extremely deficient). Number of inflorescences per plant (A); Total flowers per inflorescence (B); Floral anthesis period (C); Number of non-viable pollen grains (D). Means followed by the same lowercase did not differ from the control in $(P<0.05)$, according to the ScottKnott test; and ND means parameter not determined. Values are presented as means of ten biological replicates \pm SE. 

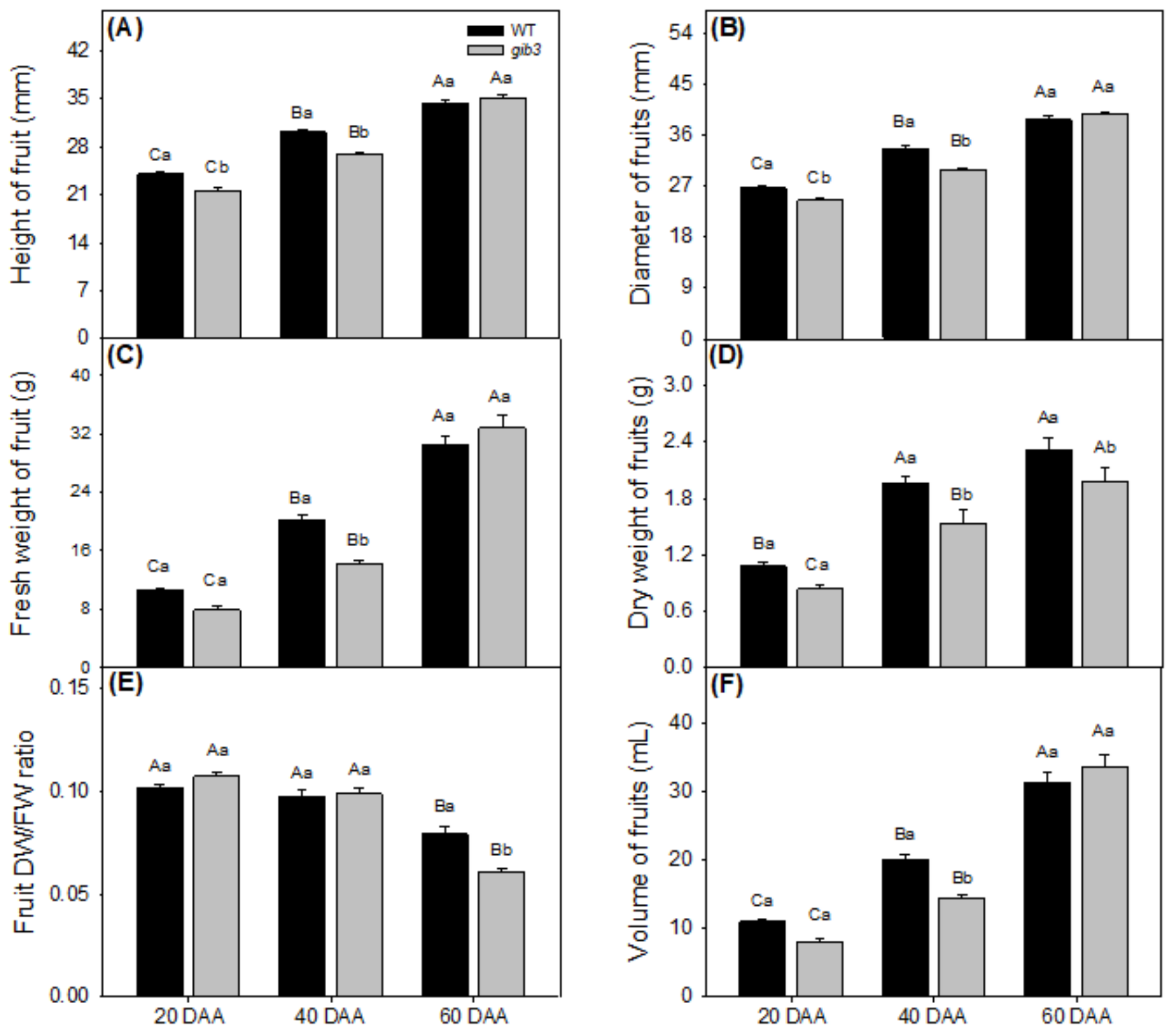

\section{Figure 3}

Variations on morphological development parameters in tomato fruits in response to reduced endogenous of GA levels in WT and mutants plants deficient in the biosynthesis of gibberellins ( $\mathrm{gib} 3$ ). The fruits were evaluated in three different ages: 20, 40 and 60 DAA. Height of fruit (A); Diameter of fruits (B); Fresh weight of fruit - FW (C); Dry weight of fruits - DW (D); Ratio DW:FW (E); Volume of fruits (F). Lowercase letters indicate significant differences between genotypes within each time, and capital letters indicate significant differences between periods within each genotype $(P<0.05)$, according to the ScottKnott test. Abbreviations as described in Figure 1. Values representthe means \pm SE of at least ten independent fruits/plants. 

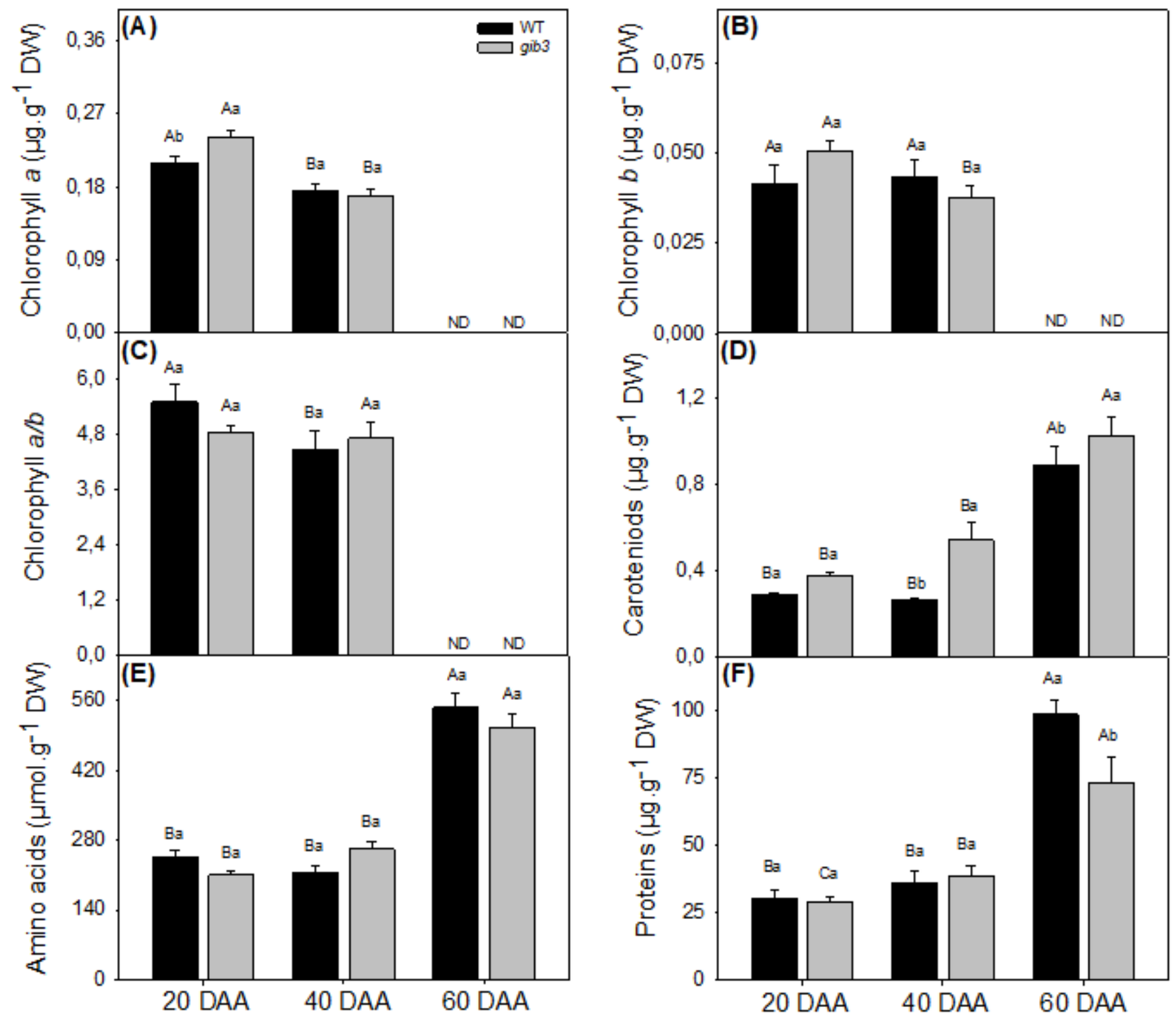

Figure 4

Variation on nitrogen metabolism in tomato fruits in response to reduced endogenous levels of GA levels in WT and mutants plants deficient in the biosynthesis of gibberellins ( $g i b 3)$. The fruits were evaluated in three different ages: 20, 40 and 60 DAA. Chlorophyll $a(\mathrm{~A})$; Chlorophyll $b(\mathrm{~B})$; Chlorophyll $a / b(\mathrm{C})$; Carotenoids (D); Amino acids (E); Total soluble proteins (F). Lowercase letters indicate significant differences between genotypes within each time, and capital letters indicate significant differences between periods within each genotype $(P<0.05)$, according to Scott-Knott test; and ND means compounds not determined. Abbreviations as described in Figure 1. Values represent the mean \pm SD of at least ten independent fruits. 

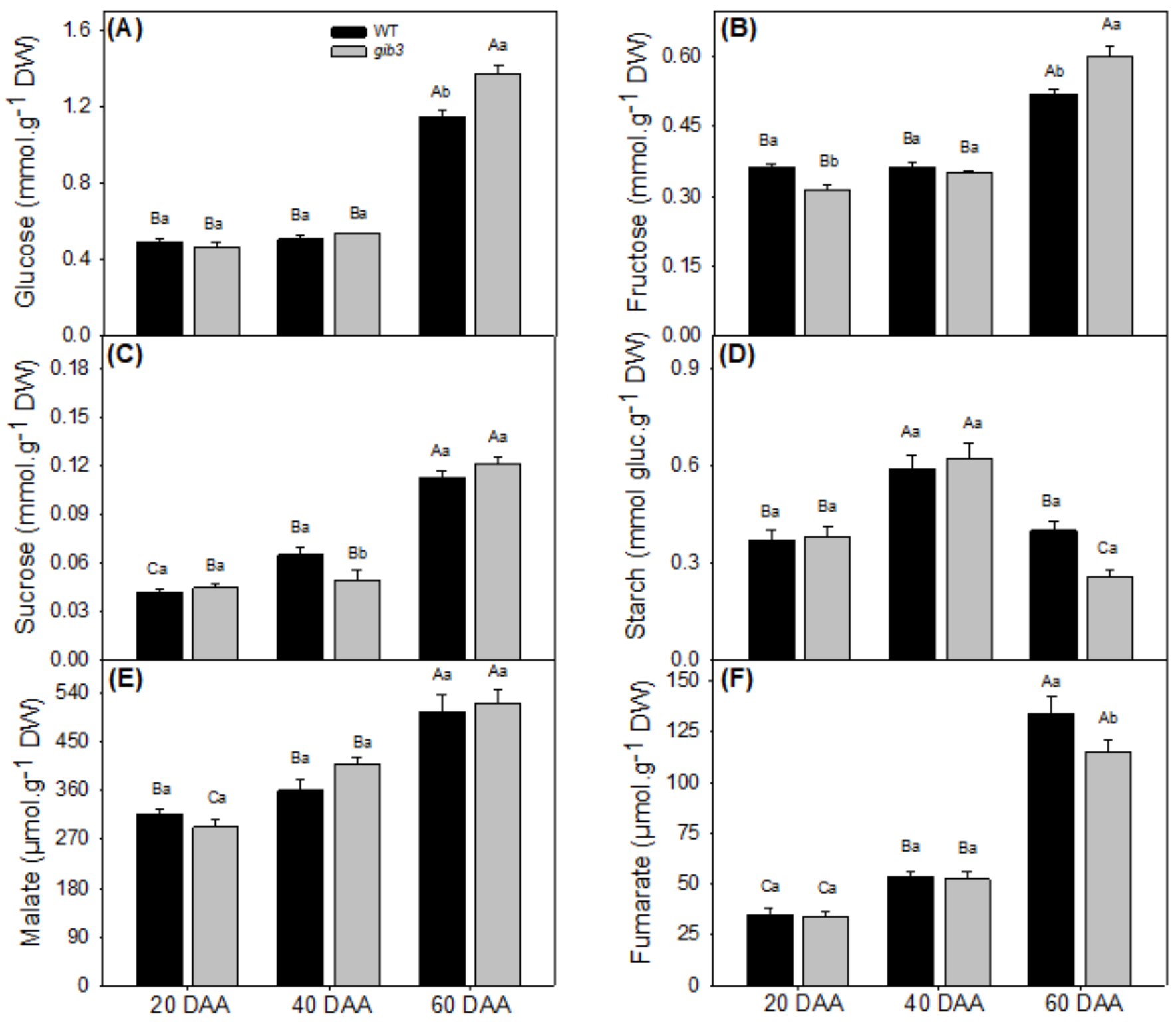

Figure 5

Variation on carbon metabolism related metabolites in tomato fruits in response to reduced endogenous levels of GA in WT and mutants plants deficient in the biosynthesis of gibberellins (gib3). The fruits were evaluated in three different ages: 20, 40 and 60 DAA. Glucose (A); Fructose (B); Sucrose (C); Starch (D); Malate $(F)$ and Fumarate $(G)$. Lowercase letters indicate significant differences between genotypes within each time, and capital letters indicate significant differences between periods within each genotype $(P<0.05)$, according to Scott-Knott test. Abbreviations as described in Figure 1. Values represent the mean \pm SE of at least ten independent fruits. 


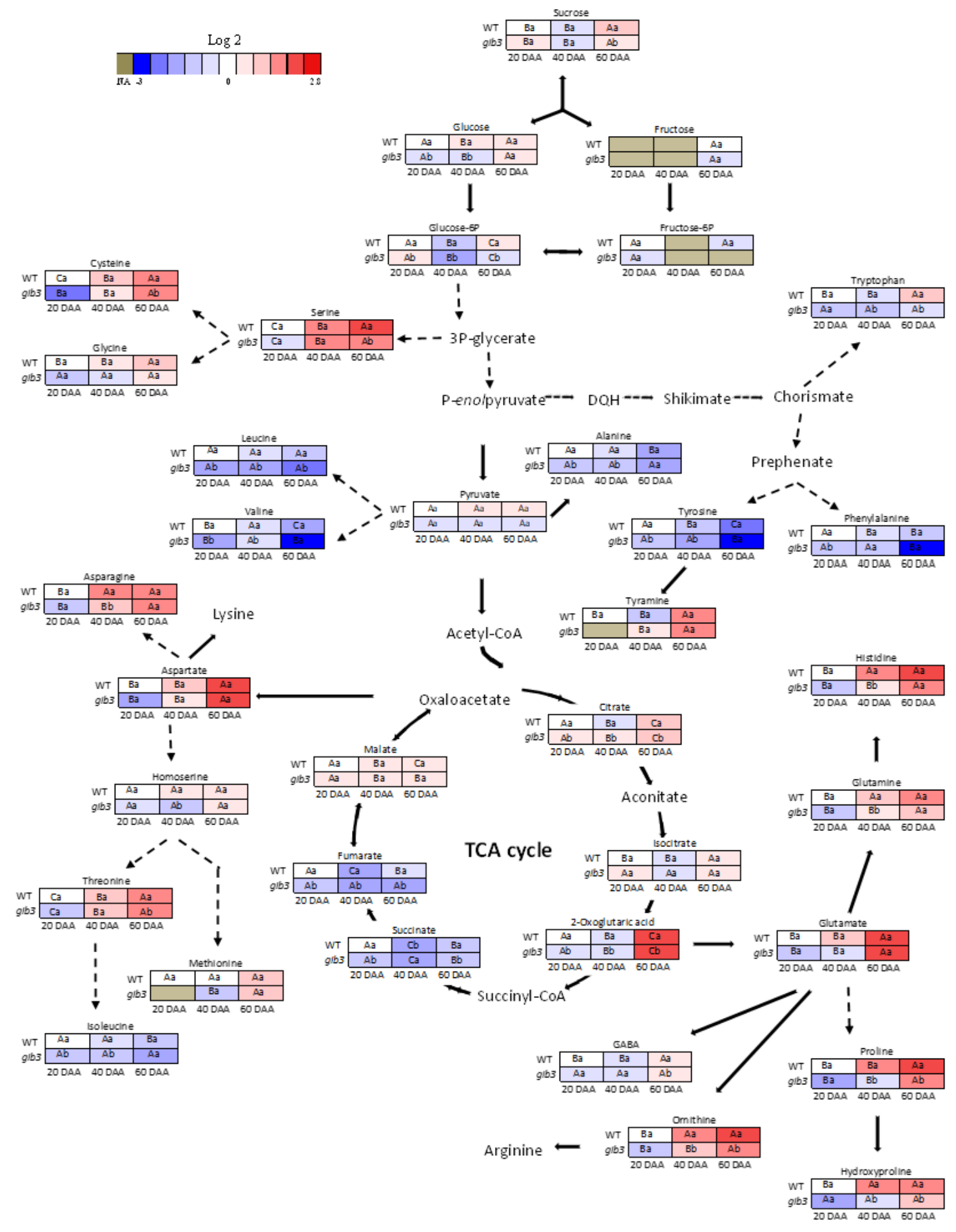

\section{Figure 6}

Variation on metabolite profiling in tomato fruits in response to reduced endogenous levels of GA levels in WT and mutants plants deficient in the biosynthesis of gibberellins (gib3). Continuous arrows indicate a one-step reaction, and broken arrows indicate a series of biochemical reactions. Lowercase letters indicate significant differences between genotypes within each time point, and capital letters indicate 
significant differences between periods within each genotype $(P<0.05)$, according to Scott-Knott test. Abbreviations as described in Figure 1.

\section{Supplementary Files}

This is a list of supplementary files associated with this preprint. Click to download.

- Supplementaryfigure1WLA.docx

- Supplementaryfigure2WLA.docx

- Supplementaryfigure3WLA.docx

- Supplementaryfigure4.docx

- Supplementaryfigure5WLA.docx

- Supplementaryfigure6.docx 